\title{
NAD precursors cycle between host tissues and the gut microbiome
}

Karthikeyani Chellappa ${ }^{1,6}$, Melanie R. McReynolds ${ }^{2,3,6}$, Wenyun Lu $^{2,3}$, Xianfeng Zeng ${ }^{2,3}$, Mikhail Makarov $^{4}$, Faisal Hayat ${ }^{4}$, Sarmistha Mukherjee ${ }^{1}$, Yashaswini R. Bhat ${ }^{1}$, Siddharth R. Lingala ${ }^{1}$, Rafaella T. Shima ${ }^{1}$, Hélène C. Descamps ${ }^{5}$, Timothy Cox ${ }^{5}$, Lixin Ji ${ }^{1}$, Connor Jankowski ${ }^{2,3}$, Qingwei Chu ${ }^{1}$, Shawn M. Davidson ${ }^{2}$, Christoph A. Thaiss ${ }^{5}$, Marie E. Migaud ${ }^{4}$, Joshua D. Rabinowtiz ${ }^{2,3,7}$ and Joseph A. Baur ${ }^{1,7}$

${ }^{1}$ Department of Physiology and Institute for Diabetes, Obesity, and Metabolism, Perelman School of Medicine, University of Pennsylvania, Philadelphia, PA

${ }^{2}$ Lewis-Sigler Institute for Integrative Genomics, Princeton University, Princeton, NJ

${ }^{3}$ Department of Chemistry, Princeton University, Princeton, NJ

${ }^{4}$ Department of Pharmacology, Mitchell Cancer Institute, College of Medicine, University of South Alabama, Mobile, $A L$

${ }^{5}$ Department of Microbiology, Perelman School of Medicine, University of Pennsylvania, Philadelphia, PA6

${ }^{6}$ These authors contributed equally

${ }^{7}$ Lead contact

*Correspondence: baur@pennmedicine.upenn.edu, joshr@princeton.edu 


\begin{abstract}
Nicotinamide adenine dinucleotide (NAD) is an essential redox cofactor in both mammals and microbes. Here we use isotope tracing to investigate the precursors supporting NAD synthesis in the gut microbiome. We find that preferred dietary NAD precursors are absorbed in the proximal part of the gastrointestinal tract and not available to microbes in the distal gut. Instead, circulating host nicotinamide enters the gut lumen and supports gut microbiome NAD synthesis. In addition, the microbiome converts nicotinamide, originating from the host circulation, into nicotinic acid. Host tissues uptake and utilize this microbiome-derived nicotinic acid for NAD synthesis, maintaining circulating nicotinic acid levels even in the absence of dietary consumption. Moreover, the main route from oral nicotinamide riboside, a widely used nutraceutical, to host NAD is via conversion into nicotinic acid by the gut microbiome. Thus, NAD precursors cycle between the host and gut microbiome to maintain NAD homeostasis.
\end{abstract}




\section{Introduction}

Nicotinamide adenine dinucleotide (NAD) is an indispensable reduction-oxidation (redox) co-enzyme. It is also a substrate for signaling enzymes including sirtuins, poly-ADP polymerases (PARPs), CD38 and SARM1. NAD-consuming enzymes degrade the NAD molecule and release nicotinamide (NAM), thus necessitating a balance between synthesis and consumption to maintain NAD homeostasis. NAD levels have been reported to decline in a spectrum of pathological conditions including aging, obesity, inflammatory, cardiovascular, and neurodegenerative diseases. In many cases, the decline in cellular NAD content correlates with mitochondrial and metabolic dysfunction. NAD boosting ameliorates metabolic perturbations in rodent models of disease ${ }^{1-5}$ and has shown promise in some human clinical trials ${ }^{6,7}$, albeit with modest or no effects in others ${ }^{8-10}$.

Animals have coevolved with commensal microorganisms, including the gut microbiome. The microbes that dwell in the gut lumen are unique in that they can potentially access both ingested food and circulating nutrients to support their metabolic activity. That said, nutrients that are absorbed in the proximal parts of the small intestine are largely inaccessible to the microorganisms residing in the gut lumen. Moreover, it is unclear which, if any, circulating host nutrients permeate the gut microbiome sufficiently to drive microbiome metabolism. Two established nutrient sources of the colonic microbiome are poorly digestible complex carbohydrates (fiber) ${ }^{11}$ and host mucus ${ }^{12-17}$.

As with host cells, NAD is essential to microorganisms. Tremendous effort has been undertaken over the past century to understand NAD metabolism in mammalian tissues and free-living microbes. In contrast, NAD metabolism in the gut microbiome is less extensively studied. A recent study revealed a profound decrease in the NADH/NAD redox ratio (but not absolute NAD levels) in colonocytes of germ-free mice ${ }^{18}$. Compared to conventional mice, germ free mice fed a western diet had higher liver $N A D^{19}$. Intriguingly, gut microbiota are required for the full NAD-boosting effect of orally delivered precursors including both NAM and the common nutraceutical nicotinamide riboside $(\mathrm{NR})^{20}$.

In mammals, three major routes of NAD biosynthesis are (1) de novo synthesis from tryptophan, (2) salvage synthesis from NAM via nicotinamide phosphoribosyltransferase (NAMPT), and (3) Preiss-Handler synthesis from nicotinic acid (which is also called "niacin") by nicotinic acid phosphoribosyltransferase (NAPRT). De novo synthesis of NAD from tryptophan is quantitatively important mainly in the liver $^{21}$, but the kidney and some immune cells also utilize this pathway to make $N A D^{22,23}$. Turnover of NAD generates NAM, which is exchanged with the systemic circulation. This provides a common pool of precursor that can be used to generate 
NAD through the salvage pathway. Nicotinic acid is obtained from the diet or microbiome, circulates at lower concentrations, and makes a quantitatively smaller contribution to NAD synthesis in most tissues ${ }^{21}$. NAD synthesis can be increased by exogenous supplementation with intermediates such as $\mathrm{NR}$ or $\mathrm{NMN}^{1,5,24-26}$. The degree to which this reflects direct incorporation of the parent molecule vs. breakdown and resynthesis is an active area of investigation $^{21}$.

Most microbial species encode one or more enzymes required to synthesize NAD either de novo from amino acids or through salvage of "vitamin B3" (a collective term for nicotinic acid, NAM and related derivates such as nicotinamide riboside and nicotinic acid riboside) ${ }^{27-30}$ (Figure 1A). In unicellular microorganisms, de novo synthesis can occur either from tryptophan (as in mammals) or more commonly from aspartate by L-aspartate oxidase $(\operatorname{nad} B)^{31}$. Importantly, many bacteria (but not mammals) encode the enzyme to convert NAM to nicotinic acid: nicotinamide deamidase $(p n c A)^{20,27,32}$.

In this study, we use isotopic tracers to determine how the microbial NAD pool is established. We find that dietary protein and vitamin B3 are not primary precursors for NAD biosynthesis in gut microbiota. Instead, NAM in the host circulation enters the gut lumen to feed NAD biosynthesis, with fiber catabolism also feeding into NAD in the colonic microbiome. Beyond consuming host-derived NAM, the microbiome converts NAM into nicotinic acid, which provides an alternative NAD precursor to host tissues, restoring NAD levels in intestinal cells when salvage synthesis of NAD from NAM is blocked. The gut microbiome also converts orally delivered NR into nicotinic acid, which circulates at high levels post oral NR and is critical to NR's capacity to boost host NAD. In short, we identify a NAM-nicotinic acid metabolic cycle that allows sharing of NAD precursors between host and microbiome.

\section{Results}

\section{Soluble fiber contributes to microbiome NAD synthesis in the large intestine}

We explored whether dietary fiber or protein provide precursors for de novo NAD biosynthesis by the gut microbiome. Grain-based chow contains around $15-20 \%$ of insoluble fiber (generally not metabolized) and 3-5\% soluble fiber ${ }^{33}$ (fermented by colon bacteria) ${ }^{27,34,35}$. We tested whether ${ }^{13} \mathrm{C}$-labeled soluble fiber (inulin) or protein feed microbiome NAD synthesis. Mice were fed a refined diet mixed with $5 \%$ unlabeled inulin $\mathrm{w} / \mathrm{w}$ for 14 days and then switched to diet with $\mathrm{U}-{ }^{13} \mathrm{C}$ inulin for $24 \mathrm{~h}$ before sacrifice. Alternatively, they were fed standard chow containing $\mathrm{U}-{ }^{13} \mathrm{C}$-labeled protein for $24 \mathrm{~h}$. We found $\sim 65 \%$ of NAD molecules contained one or more labeled carbon atoms 
derived from inulin, versus less than 10\% from protein (Figures 1B and 1C). Quantitative analysis accounting for precursor (e.g., amino acid) labeling in the cecum lumen and all carbon atoms in NAD revealed that fiber accounts for $40 \%$ of the total carbon contribution to NAD synthesis, versus only $3 \%$ for protein (Figures $1 \mathrm{D}$ and 1E, Supplementary Figure 1A). The contribution of inulin to microbial NAD synthesis was lower in other parts of the gut lumen and intestinal tissues (Supplementary Figure 1B). Fiber's contribution to microbiome NAD included labeling of the key NAM moiety, as shown by MS/MS. Consistently, labeling was also detected in luminal NAM (Supplementary Figures 1C and 1D).

Simple sugars such as fructose are normally absorbed in the proximal part of the Gl tract but may reach distal parts of the gut lumen under conditions of excessive nutrient intake ${ }^{36}$. We found that a large bolus of fructose supplied precursors for NAD synthesis by large intestinal microbiota (Supplementary Figures 1E-1J). Thus, carbohydrate that reaches the colon will feed into de novo NAD synthesis, but a large portion of NAD synthesis remains unaccounted for after considering dietary protein and fiber.

\section{Dietary nicotinic acid is not available to microorganisms residing in the distal gut}

Standard mouse chow contains nicotinic acid, which could provide a precursor for NAD synthesis by gut microbes. To examine this possibility, we gavaged mice with labeled nicotinic acid $\left(2,4,5,6-{ }^{2} \mathrm{H}-\mathrm{NA}\right)$ at a dose equivalent to one-third of daily intake. High levels of fully labeled nicotinic acid $(M+4 N A)$ were detected in the stomach lumen at the earliest time point assayed (Figure 1F). Labeled NA in the serum peaked at $15 \mathrm{~min}$ and gradually declined (Supplementary Figure $1 \mathrm{~K}$ ). Incorporation of this tracer into NAD results in loss of label from the redox-active (4) position to generate M+3 metabolites. A small amount of unmetabolized M+4 NA was found in the lumen of the duodenum and jejunum, whereas only M+3 NA was detected in the distal small intestine and colon. While oral NA made a significant contribution to microbial NAD synthesis in the duodenal lumen $(\sim 32 \%)$, the contribution was negligible in distal small intestine and large intestine (Figure 1G). These data are consistent with oral NA being absorbed or metabolized before reaching the lumen of the ileum and colon.

To establish the relative contribution of microbes to NA in the gut lumen and circulation, we next fed mice a refined diet with or without NA. Mice on each of the diets were either given normal drinking water or water treated with a cocktail of antibiotics to deplete microbiota. While antibiotics alone were sufficient to deplete NA in the gut lumen, a combination of NA-deficient diet and antibiotics was required to decrease circulating NA (Figures $1 \mathrm{H}$ and $1 \mathrm{I}$ ). 


\section{Circulating nicotinamide is a major precursor for luminal NAD and nicotinic acid}

Strikingly, while antibiotics depleted NA in the gut lumen, they augmented luminal NAM (Figure 1J). A similar decrease in luminal NA and increase in NAM were observed in the intestinal lumens of germ-free mice (Figure $1 \mathrm{~K}$, Supplementary Figures $1 \mathrm{~L}$ and $1 \mathrm{M}$ ). These data raise the possibility that there is a microbiome-independent source of gut lumen NAM, and that microbes convert this NAM into NA.

What is the source of gut lumen NAM? One possibility is the flux of circulating NAM made by the host ${ }^{37,38}$. To explore this possibility, we intravenously injected mice with $2,4,5,6-{ }^{2} \mathrm{H}$ NAM (Figure 2A). We detected fully labeled NAM in the lumen all along the Gl tract (Figure 2B). In addition, $M+4$ labeled NA was found in the luminal contents along the length of the Gl tract (Figure 2C). NA generated from infused NAM reenters the circulation as evidenced by labeled NA in serum (Figure 2D). Labeled NAD molecules were detected in the luminal contents of both the small and large intestines, indicating incorporation into the microbial pools (Supplementary Figure 2A). Similarly, intravenously delivered NAM tracer accumulated in the Gl lumens of germ-free mice (Figure 2E and Supplementary Figure 2B) but was not converted into NA and NAD (Figures 2E and 2F, Supplementary Figures $2 \mathrm{C}$ and 2D).

To rule out that the above results are due to large transient perturbations in circulating NAM levels following intravenous injection and to enable more quantitative downstream analyses, we next carried out experiments involving continuous intravenous infusion of $2,4,5,6-{ }^{2} \mathrm{H}-\mathrm{NAM}$ at a minimally perturbative rate $(0.2 \mathrm{nmol} / \mathrm{g} / \mathrm{min})$. NAM infusion resulted in a rapid increase in serum $\mathrm{M}+4$ NAM labeling and slower accumulation of circulating M+3 NAM derived from cycle(s) of NAD synthesis and breakdown in tissues (Figure $3 A)^{21,39}$. Both infused $(M+4)$ and recycled $(M+3) N A M$ were detected in the gut lumen, along with luminal and serum $M+4$ and $M+3 N A$ (Supplementary Figures $3 A-3 C$ ). NAD was labeled throughout the small intestine and colon, reaching steady-state in the ileum and jejunum lumen within 12h (Figure 3B) and colon at 18h. Despite higher uptake of NAM, labeling of NAD was slow in the stomach lumen. By normalizing to fractional NAM labeling in serum, we estimated the quantitative contribution of circulating NAM to microbiome NAD synthesis in different parts of the gastrointestinal tract (Figure 3C). Circulating NAM accounts for $80-90 \%$ of microbial NAD synthesis in the ileum and jejunum, and $45 \%$ in the colon (consistent with the colon microbiome synthesizing about half of its NAD de novo from fiber). Thus, circulating host NAM enters the gut lumen and is used by the microbiome for both NAD and NA synthesis.

\section{Microbial deamidation bypasses salvage synthesis in host intestine and liver}


Most tissues rely on the salvage pathway for NAD synthesis ${ }^{21}$. Inhibiting NAMPT, the ratelimiting enzyme in the salvage pathway, general depletes NAD levels in tissues in proportion to their NAD consumption rates ${ }^{39}$. Intestine is an exception to this trend. For example, intestine and spleen have similarly rapid NAD turnover rates, but treatment with the NAMPT inhibitor FK866 depletes $>90 \%$ of NAD in spleen, but only about $~ 50 \%$ in intestine ${ }^{39}$ (Figure 3D). Using 2,4,5,6- ${ }^{2} \mathrm{H}-\mathrm{NAM}$ tracer, we observed persistent labeling of intestinal (but not spleen) NAD from the infused NAM even in the presence of NAMPT inhibitor (Figure 3E). We hypothesized that this persistent synthesis reflects intestinal incorporation of NA made by microbial deamidation of NAM, and thus would be blocked by a combination of NAMPT inhibitor and antibiotics. Indeed, FK866 treatment dramatically decreased NAD labeling from NAM in antibiotics treated mice (Figure 3F). In the liver, treatment of mice with either FK866 or antibiotics decreased labeling of NAD from infused labeled NAM, and combined treatment completely prevented intravenous NAM from contributing to hepatic NAD (Supplementary Figure 3D). Thus, gut microbiota provide an alternative route from NAM to NAD, bypassing the salvage synthesis pathway, in intestine and liver (Figure 3G).

\section{Nicotinamide riboside boosts tissue NAD pools via breakdown and deamidation to nicotinic acid}

Nicotinamide riboside (NR) is widely promoted and consumed as an NAD-boosting nutraceutical supplement ${ }^{40}$. Intact NR can be taken up by cells and converted to NAD without the need for the energetically expensive endogenous metabolite phosphoribosyl pyrophosphate or the key salvage enzyme NAMPT. However, the majority of orally delivered NR has been shown to be rapidly cleaved to NAM before entering circulation and peripheral tissues ${ }^{21,41}$. Moreover, oral NR supplementation has recently been shown to be much less effective at boosting liver and intestinal tissue NAD levels in the absence of gut microbiota, consistent with its being incorporated via a deamidated route ${ }^{20}$. We measured circulating levels of vitamin B3 species in mice following NR oral gavage $(500 \mathrm{mg} / \mathrm{kg})$. Circulating NA increased $>100$-fold increase, peaking at $50 \mu \mathrm{M}$. NAM showed a similar trend, with more extended exposure duration and modestly higher peak concentration (Figures $4 \mathrm{~A}$ and $4 \mathrm{~B}$ ). The observed levels of NA from NR gavage are comparable to those in humans receiving therapeutic NA supplementation known to elicit effects on plasma lipids and lipoproteins ${ }^{42-44}$ and in excess of the $\mathrm{EC}_{50}$ for activation of GPR109A (the "niacin receptor") ${ }^{45-47}$.

Production of NAD and NA from NR can occur multiple ways, e.g., (i) NR to NAD to NAM to NA; (ii) NR to NAM to NA to NAD; (iii) NR to nicotinic acid riboside (NAR) to NAD and/or NA. Given that NR has been reported to be more effective than equivalent doses of NAM or 
$\mathrm{NA}^{48}$ and that metabolism of oral nicotinamide mononucleotide was recently suggested to proceed via the deamidated mononucleotide ${ }^{49}$, we were particularly intrigued by possibility (iii). To distinguish these routes, we synthesized an $\mathrm{M}+9$ isotopologue, on which ${ }^{15} \mathrm{~N},{ }^{13} \mathrm{C}$ and ${ }^{18} \mathrm{O}$ atoms have been introduced on the amide group in the NAM moiety and the five carbon atoms of the ribose ring are ${ }^{13} \mathrm{C}$ (Figure 4C). Deamidation always removes the labeled nitrogen from the amide group and reamidation has a $50 \%$ chance of removing the labeled oxygen as we $\|^{50}$. Orally delivered NR was found in the Gl tract but not in other peripheral tissues, indicating rapid metabolism of NR before it enters the circulation (Supplementary Figure 4A). Only a small fraction of NAD in the liver and small intestine were $M+9$, indicating minimal direct assimilation of NR (Supplementary Figure 4B). Thus, route (i) is a minor contributor.

In both routes (ii) and (iii), the nicotinamide moiety of NAD is expected to be labeled as a mixture of $M+1$ and $M+3$, indicating synthesis via a deamidated species: NA or NAR. The routes can be distinguished because (iii) retains the original labeled ribose moiety, which would result in production of $M+6$ and $M+8$ NAD. Only $M+1$ and $M+3$ labeled NAD molecules were detected in the gut microbiome and host tissues (Supplementary Figure 4B), indicating separation of the NAM/NA moiety from the labeled ribose: assimilation via route (ii). Consistent with this, we detected $M+1$ and $M+3$ labeled nicotinic acid adenine dinucleotide (NAAD) in tissues (Supplementary Figure 4C). As expected for NR assimilation via a deaminated species, depletion of gut microbiota with antibiotics completely eliminated NR-derived NA from serum and dramatically abrogated the effect of NR supplementation on NAD in host tissues (Figures 4D-4H, Supplementary Figures 4D-4G). Direct incorporation of NR into NAD was higher in antibioticstreated mice, but NAD synthesis from this route was not sufficient to significantly increase the total NAD pool in the absence of gut microbiota. Thus, NR is catabolized to NA by gut microbiota, and the resulting NA supports NAD synthesis in host tissues.

\section{Discussion}

Hosts and their gut microbiomes have coevolved to have complex symbiotic relationships. While it is widely perceived that microbes extend digestive capabilities and produce metabolites such as short-chain fatty acids, flux of metabolites from host to microbiome remains limited to a few examples. These include the feeding of microbes on host-derived mucus $^{12-16,51}$, incorporation of urea nitrogen into microbial protein ${ }^{52-54}$, and bidirectional transport of lactate ${ }^{55}$. In addition, host-derived bile acids are metabolized by microbes and have a suppressive effect to limit microbiome growth ${ }^{56-58}$. In each of these cases, metabolism of host molecules by the microbiome may be considered opportunistic, even if it is ultimately mutually 
beneficial. Here we describe a unique bidirectional interaction between the host and gut microbiome in sharing precursors for NAD biosynthesis.

Our results also shed light on the metabolism of dietary NAD precursors. The primary dietary precursors for NAD synthesis, amino acids derived from dietary proteins, NAM, and NA are readily absorbed in the upper Gl tract, and thus not available to microbes residing in the distal parts of the small intestine and large intestine. Even with a diet free of both NAM and NA, microbial NA production remains high enough to maintain circulating levels in the host. Soluble fiber (traced with ${ }^{13} \mathrm{C}$-inulin) accounts for just under half of NAD synthesis in the large intestine. We find that host-derived NAM almost completely supports microbiome NAD biosynthesis in the small intestine and makes up the other approximately half of NAD synthesis in the large intestine. Microbial NAD generated by any of these routes is turned over to produce NAM and NA that can be taken up by host intestinal tissues and used to regenerate NAD via the PriessHandler pathway.

The relative importance of NA-dependent (Priess-Handler pathway) NAD synthesis in mammals has been difficult to ascertain. Compared to NAM, NA circulates at a concentration that is nearly an order of magnitude lower and has a much lower turnover flux ${ }^{21,46,59}$. The rate limiting enzyme in the Preiss-Handler pathway, NAPRT, is expressed in multiple host tissues but the highest enzymatic activity levels are found in the liver and kidney ${ }^{60}$, suggesting that NA might primarily contribute to NAD synthesis in those organs. However, exogenous NA is readily incorporated into NAD in many human cell lines ${ }^{60,61}$ and some tumors amplify the NAPRT gene and depend primarily on the Priess-Handler pathway for NAD ${ }^{62-64}$.

Under conditions of increased NA availability, such as direct supplementation or provision of alternate precursors that can be converted to NA by the microbiome, the PriessHandler pathway may become more quantitatively important and other NA-dependent mechanisms may also be engaged. An important feature of NAPRT, as compared to NAMPT (NAM-dependent synthesis) is that NAPRT is not subject to feedback inhibition ${ }^{60}$. Incubation of the purified enzymes with NAD results in inhibition of $\mathrm{NAMPT}^{65}$, but not NAPRT ${ }^{66}$, and preincubation of cells with NA prevents NAM-dependent NAD synthesis, but not vice versa ${ }^{67}$. Thus, NAD levels can theoretically be increased more by NA than by NAM. In addition, NA at pharmacological doses has lipid-lowering properties and can engage GPR109A, which is responsible for a common side effect - flushing ${ }^{46,68}$. The mechanism of lipid lowering remains somewhat controversial but may involve inhibition of the diacylglycerol synthesis enzyme DGAT2 $2^{69-71}$. We find that high dose NR can lead to peak circulating NA concentrations over 50 $\mu \mathrm{M}$ in mice. This concentration is comparable to NA levels in plasma following oral NA intake in 
humans $^{42-44}$ and thus may be sufficient to transiently activate GPR109A or inhibit DGAT2, mechanisms of action that have not previously been considered relevant for NR. Importantly, if NA-dependent mechanisms play a role in the beneficial effects of NR in mice, it could help explain the lack of translation in some clinical trials - the lower doses used for human studies would be unlikely to support comparable elevation of circulating NA.

We also clarified the metabolic route from NR to NAD. Like Shats et al. ${ }^{20}$, we find that NAD boosting effect of NR depends on microbial deamidation. Our use of NR labeled at multiple different atom types additional distinguishes whether NAD synthesis from NR occurs via NAR or NA. The NAR-dependent route is attractive and would explain how NR could be more effective than either NA or NAM for boosting NAD ${ }^{48}$. Our data, however, conclusively demonstrate that NR contributes to NAD mainly via NA.

NAAD is an effective biomarker for NAD supplementation using $N R^{8-10,48}$. Although it was originally suggested to result from deamidation of $\mathrm{NAD}^{48}$, the discovery that microbes deamidate precursors led to the suggestion that it originates from $\mathrm{NA}^{20}$. The labeling patterns in our study strongly support the latter hypothesis, as labeling of NAAD matches that of NA and not NAD.

Our findings suggest some intriguing hypotheses for future investigation. The dependence of microbes on host NAM raises the possibility that the host might modulate microbiome composition or function by limiting luminal NAM transport. In addition, it is unclear whether luminal transport of NAM or microbiome NA production are influenced by stresses such as metabolic syndrome ${ }^{72-74}$. As the colonic microbiome additionally depends on complex carbohydrates that are fermented in the large intestine for NAD synthesis, increased intake of heavily processed food rich in sugar and low in dietary fiber may have a deleterious effect on NAD homeostasis. Such diets are already known to disturb microbiome composition and metabolic activity and are associated with wide range of metabolic diseases in the host ${ }^{16,75,76}$. High doses of fructose can also support NAD synthesis in the colon, consistent with recent work showing that fructose can fuel production of microbial metabolites that drive hepatic lipogenesis ${ }^{25,77}$. It will be important to determine how the cycling of NAD precursors between host and microbiome interacts with host physiology under conditions of metabolic stress.

In conclusion, we have determined the primary precursors used by small and large intestinal microbiota for NAD synthesis, leading to the identification of a vitamin B3 cycle that effectively shares NAD precursors between the host and microbes. Our findings imply that perturbation of NAD metabolism either in the host or microbes has the potential to disrupt NAD homeostasis and impact physiology in the other. 


\section{Experimental models and subject details}

All animal procedures were conducted at the University of Pennsylvania and approved by the Institutional Animal Care and Use Committee. 10-12-week-old C57BL/6J male mice were purchased from The Jackson Laboratory and acclimated for at least two weeks with ad libitum access to laboratory diet 5010 and water on 12h light: dark cycle (7AM- 7PM) before use in experiments. 8-12-week-old germ-free C57BL/6 male mice were obtained from University of Pennsylvania Gnotobiotic Mouse Facility.

\section{Method details}

\section{Colonization of germ-free mice}

For colonization of germ-free mice (Ex-GF), two adult germ-free mice were co-housed with one special pathogen free (SPF) mouse in each cage for 18 days before tissue collection.

\section{In vivo tracing of dietary protein and inulin}

${ }^{13} \mathrm{C}$ labeled diets were prepared by adding ${ }^{13} \mathrm{C}$-Crude Protein extract from algae (Sigma-Aldrich, 642878) or ${ }^{13} \mathrm{C}$-Inulin (Sigma-Aldrich, 900388) to a premix (modified from normal diet with reduced protein, inulin and starch content, Research Diets Inc., D20030303). The final enrichment for each labeled macronutrient was $25 \%$, and both labeled diets share the same macronutrient composition (63\% carbohydrate, $20 \%$ protein, $7 \%$ fat, $7.5 \%$ Inulin, $2.5 \%$ cellulose). 8-week-old male C57BL/6NCrl mice (strain 027; Charles River Laboratories) were first adapted to a compositionmatched non-labeled diet for 2 weeks to ensure minimal microbiome perturbation upon diet switch. The non-labeled diet was replaced with a diet that contained a mixture of labeled and unlabeled protein or inulin (1:3) at 9am in the morning, $24 \mathrm{hr}$ before sacrifice, during which mice were given free access to water.

\section{In vivo tracing of fructose}

Random fed 12-14-week-old C57BL/6J male mice were orally gavaged with $2 \mathrm{~g} / \mathrm{kg}$ body weight $\mathrm{U}$ ${ }^{13} \mathrm{C}$-Fructose (Cambridge Isotope Laboratories, Tewksbury, MA) dissolved in normal saline. Mice were sacrificed $2 \mathrm{~h}$ after fructose delivery.

\section{In vivo tracing of NA}


10 to 12 -week-old C57BL/6J male mice were orally gavaged with $1.96 \mu$ moles of $2,4,5,6-{ }^{2} \mathrm{H}-\mathrm{NA}$ (Cambridge Isotope Laboratories, Tewksbury, MA), a dose equivalent to one-third of dietary intake of NA per day (Manufacturer data show that rodent chow contains 120 ppm nicotinic acid). Blood samples were collected before gavage, $30 \mathrm{~min}$ after NA delivery and the time of sacrifice. Luminal contents and intestinal tissues were collected from the indicated parts of the Gl tract.

\section{Antibiotic treatment}

To deplete gut microbiota mice were given a combination of ampicillin $(1 \mathrm{~g} / \mathrm{L})$, vancomycin $(0.5 \mathrm{~g} / \mathrm{L})$, neomycin $(1 \mathrm{~g} / \mathrm{L})$, metronidazole $(0.5 \mathrm{~g} / \mathrm{L})$, ciprofloxacin $(0.2 \mathrm{~g} / \mathrm{L})$, and primoxin $(0.5 \mathrm{~g} / \mathrm{L})$ in drinking water for 3-5 weeks before use in experiments.

\section{NA diet feeding experiments}

Custom diets with or without NA were purchased from Research Diets Inc. Cellulose (BW200) and inulin were used as fiber source, and macronutrient and fiber levels were matched to 5010 chow diet. NA diets used to feed germ-free mice were made with $1.5 \mathrm{X}$ vitamins and mineral acid casein and subjected to two rounds of gamma-irradiation. 14-week-old C57BL/6J male mice housed in SPF condition were fed the diets with or without NA and given normal drinking water or drinking water with antibiotics cocktail for five weeks. Germ-free and conventional mice were fed with doubleirradiated diets for two weeks.

\section{In vivo tracing of isotopically labeled NAM}

2,4,5,6- ${ }^{2} \mathrm{H}$-NAM was purchased from Cambridge Isotope Laboratories (Tewksbury, MA). 2,4,5,6- ${ }^{2} \mathrm{H}$ NAM tracer was either dissolved in PBS (retro-orbital injection) or normal saline (intravenous infusions). C57BL/6J male mice were retro-orbitally injected with $0.2-5 \mu$ moles of $2,4,5,6-{ }^{2} \mathrm{H}-\mathrm{NAM}$ in $100 \mu \mathrm{l}$ volume, blood samples were collected from the tail vein either $15 \mathrm{~min}$ or $2 \mathrm{~h}$ after injection as indicated in the figure legend and mice were anesthetized to collect blood samples from the portal vein and hepatic vein. Mice were immediately euthanized by cervical dislocation and tissues were collected and clamped in liquid nitrogen.

For intravenous infusion, mice were surgically implanted with a catheter in the right jugular vein and the infusion was performed within a week. NAM tracer infusion was performed as described previously ${ }^{20}$. Briefly, $4 \mathrm{mM} 2,4,5,6-{ }^{2} \mathrm{H}-\mathrm{NAM}$ tracer was infused via the jugular catheter at a constant rate of $0.2 \mathrm{nmol} / \mathrm{g}$ body weight/min for different period as indicated in the figure legends. Blood samples $(\sim 20 \mu \mathrm{l})$ were collected from the tail vein using microvette blood collection tubes (Sarstedt, 
Cat. \# 16.440.100). At the end of the infusion period, mice were euthanized by cervical dislocation and tissues were quickly dissected and clamped in liquid nitrogen.

\section{FK866 treatment}

C57BL6/J or C57BL/6J.Nia male mice given normal drinking water or pre-treated with antibiotics cocktail for four weeks to deplete gut microbiota. Mice were injected with vehicle (45\% Propylene glycol, 5\% Tween 80, 50\% water) or 50 mg/kg FK866 (Selleck Chemicals, Houston, Tx) once (5h NAM infusion) or three times at $8 \mathrm{hr}$ intervals (23h NAM infusion). NAM infusion was started 1h after the first FK866 treatment and mice were sacrificed after $5 \mathrm{~h}$ or $23 \mathrm{~h}$.

\section{Synthesis of M+9 NR}

Scheme 1: Synthesis of silylated M+4 NAM

Scheme 2: Synthesis of silylated M+9 Nicotinamide riboside
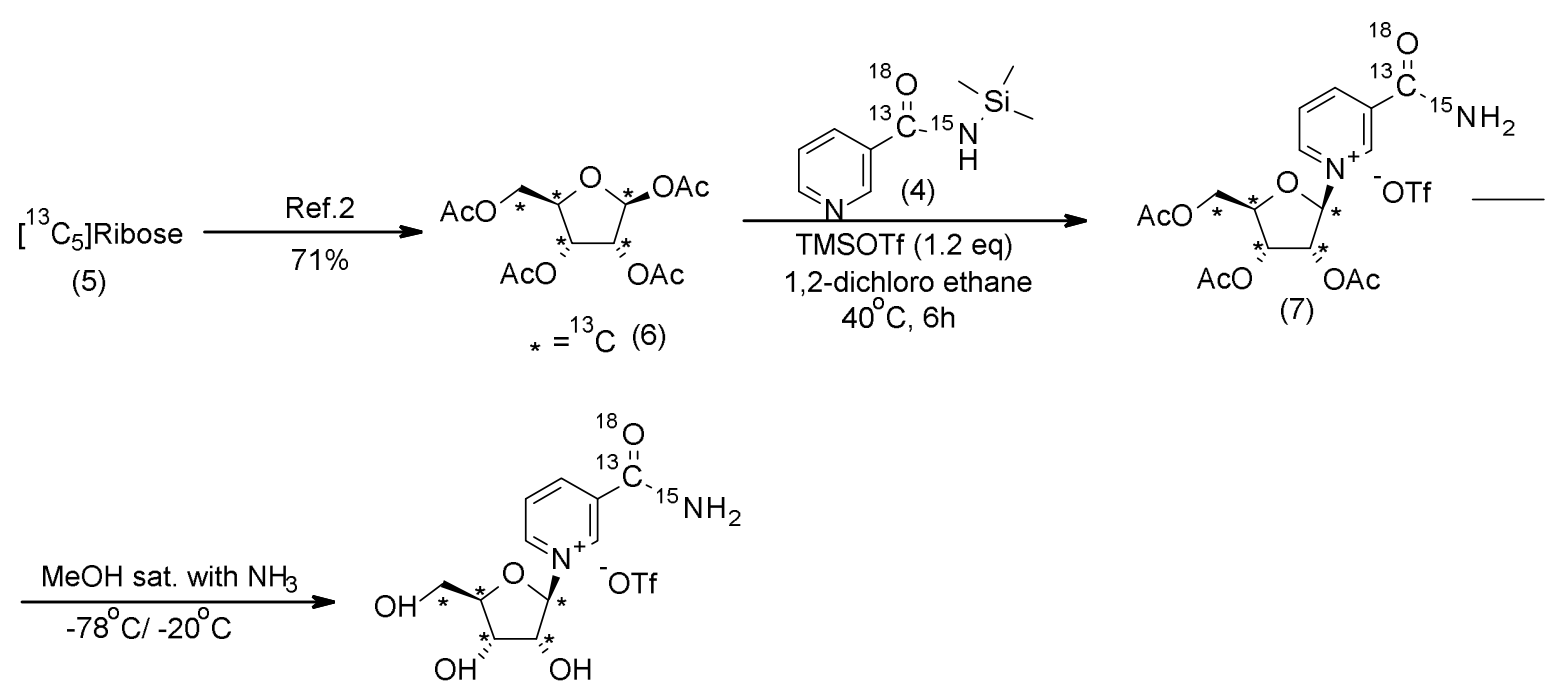

(8)

[A] Synthesis of ${ }^{13} \mathrm{C},{ }^{18} \mathrm{O}$ and ${ }^{15} \mathrm{~N}$ labelled $\mathrm{M}+4$ nicotinamide (3, Scheme 1) : Compound (3) was prepared according to reported procedure ${ }^{20}$

[B] Synthesis of Silylated M+4 NAM (4, Scheme 1): A mixture of ${ }^{13} \mathrm{C},{ }^{18} \mathrm{O}$ and ${ }^{15} \mathrm{~N}$ labelled $\mathrm{M}+4$ NAM (0.40 g; $0.032 \mathrm{~mol})$, HMDS (9.00 mL) and TMSCl $(0.81 \mathrm{~mL}, 0.70 \mathrm{~g}, 0.0064 \mathrm{~mol})$ was heated in an oil bath at $105^{\circ} \mathrm{C}$ (oil bath temperature) for 20 hours. Upon completion, the reaction mixture was allowed to cool down to room temperature and clear colorless solution was transferred into a $25 \mathrm{~mL}$ round-bottom single-neck flask under argon through a cannula and 
evaporated to dryness on a rotary evaporator followed by drying under high vacuum to give a white crystalline product $(0.623 \mathrm{~g}, 100 \%)$.

[C] Synthetic of 1,2,3,5-Tetra-O-acetyl- $\alpha / \beta-D-\left[{ }^{13} C_{5}\right]$ ribofuranoside $\left(\left[{ }^{13} C_{5}\right] R T A, 6\right.$, Scheme 2$)$ : Compound (6) was prepared according to reported procedure ${ }^{78}$

[D]General procedure for the synthesis of M+9 NR

Synthesis of M+9 NR 2,3,5-triacetate (Vorbruggen glycosylation, compound 7, Step-1): In a flame dried flask under an argon atmosphere, M+4 silylated NAM (0.37g, 0.00187 mol, 1eqv) and $\mathrm{M}+5,{ }^{13} \mathrm{C}$ labelled -d-ribose tetraacetate $(0.664 \mathrm{~g}, 0.00206 \mathrm{~mol}, 1.1 \mathrm{eqv})$ were added to dry 1,2-dichloroethane (12mL). After 5 minutes stirring at rt, TMSOTf $(0.40 \mathrm{~mL}, 0.00224 \mathrm{~mol}$, 1.2eqv) was added to the stirred 1,2-dichloroethane solution at the same temperature. Now, the resulting mixture was stirred at $40{ }^{\circ} \mathrm{C}$ until complete disappearance of the starting materials. The reaction progress was monitored by ${ }^{1} \mathrm{H}$ NMR analysis of the crude mixture. Upon completion, the resulting solution was concentrated, and the yellow oily crude product was used directly for the next step without purification.

Synthesis of $M+9 N R$ (de-esterification, compound 8, step-4,): Into a pressure tube closed with a septum, evacuated and filled with argon, $\left[{ }^{13} \mathrm{C},{ }^{18} \mathrm{O},{ }^{15} \mathrm{~N}\right]-\mathrm{NRTA}$-OTf $(1.14 \mathrm{~g}, 0.00187 \mathrm{~mol}$, 1eqv) was dissolved in anhydrous methanol $(30 \mathrm{~mL})$. The solution was cooled down to $-78^{\circ} \mathrm{C}$ at stirring, and ammonia gas (passed through a tube filled with $\mathrm{NaOH}$ ) was bubbled into the solution through a long metal needle for ca. $5 \mathrm{~min}$. The reaction solution was additionally stirred at $-78^{\circ} \mathrm{C}$ for $10 \mathrm{~min}$, and, subsequently, the septum was removed, and the tube was immediately closed with a threaded PTFE cap and transferred into a freezer $\left(-20^{\circ} \mathrm{C}\right)$ and kept at $-20^{\circ} \mathrm{C}$ for 6 days. The pressure tube was transferred into an ice bath, and, by using a cannula, the content of the tube was transferred into a recovery flask, cooled down in the same ice bath to $0^{\circ} \mathrm{C}$. The recovery flask was attached to a rotary evaporator, and ammonia gas was evaporated without any external heating and immersion in a water bath which resulted in a continuous maintaining of the solution temperature below $0^{\circ} \mathrm{C}$. After removal of ammonia, residual methanol was removed at $\mathrm{ca} .25^{\circ} \mathrm{C}$ and an oily residue was kept under high vacuum to give a viscous yellow liquid (1.0g). According to the ${ }^{1} \mathrm{H}$ NMR data, the product was contained with the mixture of acetamide, methanol and $2.9 \%$ of $\mathrm{M}+4 \mathrm{Nam} .{ }^{1} \mathrm{H} \mathrm{NMR}(400 \mathrm{MHz}, \mathrm{D} 2 \mathrm{O}, \delta$, ppm): 9.53 (s, 1H, Ar-H), $9.20(\mathrm{~s}, 1 \mathrm{H}, \mathrm{Ar}-\mathrm{H}), 8.93-8.91(\mathrm{~m}, 1 \mathrm{H}, \mathrm{Ar}-\mathrm{H}), 8.23-8.19(\mathrm{~m}, 1 \mathrm{H}, \mathrm{Ar}-\mathrm{H})$, $6.18(\mathrm{~d}, \mathrm{~J}=177 \mathrm{~Hz}, 1 \mathrm{H}, \mathrm{H}-1)$, 4.66-3.99 (m, 3H, H-2, H-4\&H-3), 3.82-3.79 (m, 1H, H-5a), 3.283.27 (m, 1H, H-5b); ${ }^{13} \mathrm{C}$ NMR (100 MHz; $\left.\mathrm{D}_{2} \mathrm{O}, \delta, \mathrm{ppm}\right): 170.60$ (d, J=17.5Hz, CO), 165.69 (d, $\mathrm{J}=18.7 \mathrm{~Hz}, \mathrm{CH}_{3} \mathrm{CONH}_{2}$ ), 145.62 ( $\left.d, \mathrm{~J}=1.18 \mathrm{~Hz}, \mathrm{C}-6_{\mathrm{NAM}}\right), 142.60$ (C-2 $\left.{ }_{\mathrm{NAM}}\right), 140.34$ (C-4 $4_{\text {NAM }}$ ), 133.40 (d, J=56.8Hz, C-3 $3_{\text {NAM }}$ ). 128.33 (d, J=3.29Hz, C-5 ${ }_{\text {NAM }}$ ), 99.91 (dd, J= $40.02 \mathrm{~Hz} \& 3.08 \mathrm{~Hz}$, 
C-1 $1_{\text {ribose }}$ ), 87.67 (t, J= 39.9 Hz, C-4 ribose $), 77.42$ (t, J=38.32 Hz, C-2 ribose $), 69.75$ (t, J= 36.19 Hz, C$3_{\text {ribose }}$ ), 60.17 (d, J= $\left.41.06 \mathrm{~Hz}, \mathrm{C}-5_{\text {ribose }}\right) ;{ }^{19} \mathrm{~F} \mathrm{NMR} \mathrm{(377} \mathrm{MHz,} \mathrm{D} 2 \mathrm{O}$ ) $\delta \mathrm{F}:-78.82$ (s); HRMS calcd for ${ }^{13} \mathrm{C}_{6}{ }^{12} \mathrm{C}_{5} \mathrm{H}_{15}{ }^{15} \mathrm{~N}^{14} \mathrm{~N}^{18} \mathrm{O}^{16} \mathrm{O}_{4}[\mathrm{M}]^{+} 264.1189$ found 264.1194.

\section{NR oral gavage}

For NR experiments mice were orally gavaged with NR (500mg/kg body weight) or a mixture of custom-synthesized M+9 NR and unlabeled NR at a ratio of 1:2.6 in PBS (600 mg/kg body weight). Blood samples were collected at different time points. Three hours after oral dosing, mice were anaesthetized to collect blood samples from hepatic and tail veins and sacrificed by cervical dislocation to collect tissues. In cases where the tracer was diluted with unlabeled molecules, the ratio was verified by mass spectrometry and used to correct for the total contribution of the administered molecule to a given metabolite of interest. This method is expected to be accurate for following any single molecule, but could underestimate the frequency of two labeled molecules coming together by chance, such as regeneration of labeled NR or NAR in the intestinal lumen from labeled ribose and NAM or NA.

\section{Metabolite extraction from serum and tissue samples}

Serum samples were thawed on wet ice before metabolite extraction. 50 ul of $100 \%$ methanol was added to $5 \mathrm{ul}$ serum, vortexed and incubated on dry ice for 10 minutes, and centrifuged at $16,000 \mathrm{~g}$ for 20 minutes, and $10 \mathrm{ul}$ of water was added to $40 \mathrm{ul}$ of serum extracts and use for LC-MS analysis. Frozen tissues were weighed and ground with liquid nitrogen in a mortar and pestle or cryomill (Retsch). Cryomilled tissues were extracted with 40:40:20 acetonitrile:methanol:water (25 $\mathrm{mg}$ tissue / $\mathrm{ml}$ extraction buffer), vortexed and incubated on ice for $10 \mathrm{~min}$. Tissue samples were then centrifuged at $16,000 \mathrm{~g}$ for 30 minutes. The tissue supernatants were transferred to new Eppendorf tubes and then centrifuged again at 16,000 $\mathrm{g}$ for 25 minutes to remove and residual debris before LC-MS analysis.

\section{Metabolite Measurements}

Extracts were analyzed within 36 hours by liquid chromatography coupled to a mass spectrometer (LC-MS). The LC-MS method involved hydrophilic interaction chromatography (HILIC) coupled to the Q Exactive PLUS mass spectrometer (Thermo Scientific) as reported previously $^{79}$. The LC separation was performed on a XBridge BEH Amide column (150 mm 3 $2.1 \mathrm{~mm}, 2.5 \mathrm{~mm}$ particle size, Waters, Milford, MA). Solvent A is 95\%: 5\% H2O: acetonitrile with $20 \mathrm{mM}$ ammonium bicarbonate, and solvent $B$ is acetonitrile. The gradient was $0 \mathrm{~min}, 90 \% \mathrm{~B} ; 2$ 
$\min , 90 \%$ B; $3 \min , 75 \% ; 7 \min , 75 \%$ B; $8 \mathrm{~min}, 70 \%, 9 \min , 70 \%$ B; $10 \min , 50 \%$ B; $12 \min , 50 \%$ B; $13 \mathrm{~min}, 25 \% \mathrm{~B} ; 14 \mathrm{~min}, 25 \% \mathrm{~B} ; 16 \mathrm{~min}, 0 \% \mathrm{~B}, 20.5 \mathrm{~min}, 0 \% \mathrm{~B} ; 21 \mathrm{~min}, 90 \% \mathrm{~B} ; 25 \mathrm{~min}, 90 \%$ B. Other LC parameters are: flow rate $150 \mu \mathrm{l} / \mathrm{min}$, column temperature $25^{\circ} \mathrm{C}$, injection volume $10 \mu \mathrm{L}$ and autosampler temperature was $5^{\circ} \mathrm{C}$. The mass spectrometer was operated in both negative and positive ion mode for the detection of metabolites. Other MS parameters are: resolution of 140,000 at $\mathrm{m} / \mathrm{z} 200$, automatic gain control (AGC) target at 3e6, maximum injection time of $200 \mathrm{~ms}$ and scan range of $\mathrm{m} / \mathrm{z}$ 75-1000. Raw LC/MS data were converted to $\mathrm{mzXML}$ format using the command line "msconvert" utility ${ }^{80}$. Data were analyzed via the MAVEN software using in-house metabolite library established from authentic standards.

Nicotinate was detected with a 13-min method using the same LC buffers and column but a different gradient at a flow rate of $300 \mu \mathrm{l} / \mathrm{min}$ : $0 \mathrm{~min}, 90 \% \mathrm{~B} ; 2 \mathrm{~min}, 90 \% \mathrm{~B} ; 5 \mathrm{~min}, 0 \% \mathrm{~B} ; 8 \mathrm{~min}$, $0 \% \mathrm{~B} ; 9 \mathrm{~min}, 90 \% \mathrm{~B} ; 13 \mathrm{~min}, 90 \% \mathrm{~B}$. A SIM scan was used covering m/z 120 - 130 in positive mode.

MS2 of unlabeled and labeled NAD: targeted MS2 was performed using the PRM function with the parent ions at $\mathrm{m} / \mathrm{z} 664.1,669.1,674.1$ and NCE 20\%. Other parameters are, resolution 17500, AGC target 5e5, maximum injection time $200 \mathrm{~ms}$, isolation window $1.5 \mathrm{~m} / \mathrm{z}$. LC condition was the same as the above 25 -min method for water soluble metabolites.

\section{Statistical analysis}

Unless otherwise noted, data are presented as mean \pm SEM. One-way or two-way ANOVA was used with Tukey's post-hoc test for comparisons of 3 or more groups. Student's t-test was used for 2 group comparisons or to determine nominal significance. Asterisks displayed in the figure denote statistical significance $(\mathrm{p}<0.05 ; * *, \mathrm{p}<0.01 ; * * *, \mathrm{p}<0.001)$.

\section{Acknowledgments:}

This work was funded and supported by a Crohn's and Colitis Career Development Award to KC; the Howard Hughes Medical Institute and Burroughs Wellcome Fund via the PDEP and Hanna H. Gray Fellow Programs awarded to MRM; NIH grants CA211437 to WL, DP1DK113643 to JDR, R01DK098656 and R01AG043483 to JAB. We acknowledge support from the Regional Metabolomics and Fluxomics Core and the Rodent Metabolic Phenotyping Core of the Penn Diabetes Research Center P30-DK19525 and S10-OD025098, as well as the CINJ Cancer Center Support Grant, Rutgers Cancer Institute of New Jersey Metabolomics Shared Resource, supported, in part, with funding from NCI-CCSG P30CA072720-5923. 


\section{Author Contributions:}

KC, MRM, JDR, and JAB conceived and designed the project. KC and MRM performed and analyzed most experiments. WL, XZ, YRB, SRL, HCD, TC, LJ, and CJ performed specific in vivo experiments and analyses. MM, FH, and MEM designed and synthesized M+9 NR. KC and JAB wrote the manuscript with input from all authors.

\section{Competing Interests Statement:}

J.D.R. is a consultant to Pfizer and an advisor and stock owner in Colorado Research Partners, L.E.A.F. Pharmaceuticals, Rafael Pharmaceuticals, Raze Therapeutics, Kadmon Pharmaceuticals, and Agios Pharmaceuticals. J.D.R. is co-inventor of SHIN2 and related SHMT inhibitors, which have been patented by Princeton University, and that he is a co-founder of Toran Therapeutics. J.A.B. is consultant to Pfizer and Cytokinetics, an inventor on a patent for using NAD precursors in liver injury, and has received research funding and materials from Elysium Health and Metro International Biotech, both of which have an interest in NAD precursors. The remaining authors have nothing to declare.

\section{Figure Legends}

Figure 1. The majority of microbial NAD synthesis is not accounted for by dietary precursors.

A. Different pathways used for NAD biosynthesis in microbes.

B. Enrichment of carbon labeled NAD in the cecal lumen of mice fed with $U-{ }^{13} \mathrm{C}$-inulin for $24 \mathrm{~h} . \mathrm{n}=3$ mice per group.

C. Enrichment of carbon labeled NAD in the cecal lumen of mice fed with $U-{ }^{13} \mathrm{C}$-protein for $24 \mathrm{~h} . \mathrm{n}=3$ mice per group.

D. Contribution of $U-{ }^{13} \mathrm{C}$-protein and $U-{ }^{13} \mathrm{C}$-inulin to $\mathrm{NAD}$ synthesis in the cecal lumen of mice treated as in B and C.

E. Enrichment of carbon labeled tryptophan, aspartate, and ribose phosphate in cecal lumen of mice treated as in $\mathrm{B}$.

F. Labeled and unlabeled NA content and fraction NAD (B) in the gut lumen after oral gavage of $1.96 \mu$ moles of $\left[2,4,5,6-{ }^{2} \mathrm{H}\right]-\mathrm{NA}$, equivalent to one-third daily dietary nicotinic acid intake.

G. Fraction labeled NAD in the gut lumen of mice treated as in F.

$\mathrm{H}$. NA content in the colonic lumen of conventional mice fed diet with $\left(\mathrm{NA}^{+}\right)$or without nicotinic acid $\left(N A^{-}\right)$that were on drinking water or antibiotics cocktail (ABX). $n=4$ per group.

I. NA content in the serum of mice treated as in $\mathrm{H}$. $\mathrm{n}=9-10$ mice per group. 
J. NAM content in the colonic lumen of mice treated as in $\mathrm{H}$. $\mathrm{n}=4$ per group.

K. Abundance of NAM in the colonic lumen of germ-free (GF) and germ-free mice colonized with microbiota from specific pathogen free mice (Ex-GF). $n=4$ per group.

Figure 2. Circulating NAM enters the gut lumen and supports microbial NAD biosynthesis.

A. NAM levels in the serum samples collected from portal (PV), hepatic (HV) and tail vein (TV) 15 min after retro-orbital injection of different doses of $\left[2,4,5,6{ }^{2} H\right]-N A M . n=2-3$ mice per group.

B. Labeled NAM detected in the lumen samples collected from mice treated as in A.

C. Labeled and unlabeled NA detected in the luminal samples collected from mice treated as in A.

D. Labeled and unlabeled NA detected in the serum samples collected from mice treated as in A.

E. Labeled and unlabeled NAM in luminal samples collected from germ-free (GF) and conventional (Conv) mice retro-orbitally injected with $5 \mu$ moles of $\left[2,4,5,6-{ }^{2} \mathrm{H}\right]-\mathrm{NAM}$ and sacrificed after $2 \mathrm{~h} . \mathrm{n}=4$ mice per group.

F. Labeled and unlabeled NA in the luminal samples collected from mice treated as in E.

\section{Figure 3. Vitamin B3 cycles between host and microbiome.}

A. Fraction labeling of nicotinamide in the serum of mice infused with $4 \mathrm{mM}\left[2,4,5,6-{ }^{2} \mathrm{H}\right]-\mathrm{NAM}$ for different time points. $n=2-4$ mice per group.

B. Fraction labeled NAD in the luminal content of mice infused as in A.

C. Percent contribution of circulating NAM to NAD synthesis in different parts of the gastrointestinal tract.

D. Relative levels of total NAD in mice intraperitoneally injected with vehicle or FK866 and infused with $\left[2,4,5,6-{ }^{2} \mathrm{H}\right]-\mathrm{NAM}$ for $24 \mathrm{~h}$. $\mathrm{n}=5-6$ mice per treatment group.

E. Fraction labeled NAD in mice treated as in D.

Data for spleen in D and E was previously reported in McReynolds et al. Cell system, 2021.

F. Fraction labeled $N A D$ in tissues collected from control and antibiotics (ABX) treated mice intraperitoneally injected with vehicle or FK866 and infused with $\left[2,4,5,6-{ }^{2} \mathrm{H}\right]$-NAM for $5 \mathrm{~h} . \mathrm{n}=3-5$ mice per treatment group.

G. Model showing a vitamin B3 cycle between host and microbes. Host-derived NAM in the circulation enters the gut lumen and is deamidated to NA by the microbiome. In turn, host tissues use microbiome-produced NA for synthesis of NAD, which is turned over to release NAM.

Figure 4. Oral NR supports NAD synthesis in mammalian tissues mainly via conversion to NA. 
A. Serum concentration of NA in mice orally gavaged with NR at a dose of $500 \mathrm{mg} / \mathrm{kg}$ body weight $\mathrm{n}=3$ per group.

B. Serum NAM concentration in mice treated as in $A$.

C. M+9 NR isotopically labeled in the amide group of nicotinamide moiety and ribose ring to establish the molecular fate of NR in host and microbes.

D. Relative level of NA in the serum of control and antibiotics (ABX) treated mice orally gavaged with PBS (vehicle) or NR at a dose of $600 \mathrm{mg} / \mathrm{kg}$ body weight. Serum samples were collected from portal vein $(P V)$, hepatic vein $(\mathrm{HV})$ and tail vein $(\mathrm{TV})$ after $3 \mathrm{~h}$ of treatment $(n=4-5$ per treatment group).

E. NAD isotopologues detected in the liver of mice treated as in D.

F. NAD isomers in the kidney of mice treated as in D.

G. Isotopologues of NAD in the intestinal tissues of mice treated as in D.

$\mathrm{H}$. Labeling pattern of NAD in the luminal samples collected from mice treated as in D.

\section{Supplementary Figure 1. Site-specific use of dietary NAD precursors by microbes along the Gl tract.}

A. Contribution of $U-{ }^{13} \mathrm{C}$-protein to aspartate and tryptophan levels in the cecum lumen of mice fed with labeled protein diet. $\mathrm{n}=3$ mice.

B. Contribution of $\mathrm{U}^{13} \mathrm{C}$-inulin to NAD synthesis in different parts of gastrointestinal tract of mice fed with labeled protein. $n=2$ mice.

C. Contribution of $\mathrm{U}^{-13} \mathrm{C}$-inulin to nicotinamide in the gut lumen of mice treated as in $\mathrm{B} . \mathrm{n}=2$ mice.

D. $M S^{2}$ fragments of $N A D$ detected in the cecum lumen of mice fed with $U-{ }^{13} \mathrm{C}$-inulin fed as in $\mathrm{B}$.

E-F. Enrichment of NAD labeling $(E)$ and contribution to NAD synthesis $(F)$ in mice orally gavaged with $U-{ }^{13} \mathrm{C}$-fructose for $2 \mathrm{~h}$ at a dose of $2 \mathrm{~g} / \mathrm{kg} . \mathrm{n}=4$ mice.

G-I. Enrichment of aspartate $(\mathrm{G})$ ribose phosphate $(\mathrm{H})$ and quinolinic acid (I) labeling in mice treated as in $\mathrm{E}$.

J. $M S^{2}$ fragments of NAD detected in the colonic lumen of mice treated as in $E$.

K. Labeled and unlabeled NA in the serum after oral gavage of $1.96 \mu$ moles of $\left[2,4,5,6-{ }^{2} \mathrm{H}\right]-\mathrm{NA}$ $\mathrm{n}=2-6$.

L. NA content in the lumen of germ free (GF) and conventional (Conv) mice fed diet with (NA ${ }^{+}$) or without nicotinic acid (NA-). $n=4-5$ mice per group.

M. Abundance of NA in the colonic lumen of germ-free (GF) and Ex-germ free (Ex-GF) mice colonized with microbiota from SPF mice. $n=4$ per group. 


\section{Supplementary Figure 2. Circulating NAM labels luminal NAD.}

A. Fraction labeled NAD in luminal contents collected from mice retro-orbitally injected with 5 $\mu$ moles $\left[2,4,5,6-{ }^{2} \mathrm{H}\right]-\mathrm{NAM}$ and sacrificed after $15 \mathrm{~min} . \mathrm{n}=2-3$ mice per group.

B. NAM levels in the serum samples collected from germ-free (GF) and conventional (Conv) mice $2 \mathrm{~h}$ after retro-orbitally injection of either PBS or $5 \mu$ moles of $\left[2,4,5,6-{ }^{2} \mathrm{H}\right]-\mathrm{NAM} . \mathrm{n}=4$ mice per group.

C. Serum NA labelling in mice treated as in B.

D. Fraction labeled NAD in the luminal samples collected from mice treated as in B.

\section{Supplementary Figure 3. The gut microbiome provides metabolic flexibility to bypass}

\section{salvage synthesis in liver.}

A. Fraction isotope labeling of NAM in the lumen of mice intravenously infused with $4 \mathrm{mM}[2,4,5,6-$

$\left.{ }^{2} \mathrm{H}\right]$-NAM. $\mathrm{n}=2-4$ mice per group.

B. Fraction isotope labeling of NA generated by microbial deamidation of $\left[2,4,5,6-{ }^{2} \mathrm{H}\right]-\mathrm{NAM}$ in mice treated as in $\mathrm{A}$.

C. Labeling of serum NA in mice infused as in A.

D. Fraction labeled NAD in the liver from control and antibiotics (ABX) treated mice intraperitoneally injected with vehicle or FK866 and infused with [2,4,5,6- $\left.{ }^{2} \mathrm{H}\right]-\mathrm{NAM}$ for $5 \mathrm{~h}$. $\mathrm{n}=3-5$ mice per treatment group.

\section{Supplementary Figure 4. The gut microbiome is required to generate deamidated precursors} from orally delivered NR.

A-C. NR (A), NAD (B), and NAAD (C) labeling in the lumen and tissues of a mouse orally gavaged with NR at a dose of $600 \mathrm{mg} / \mathrm{kg}$ body weight) for $3 \mathrm{~h}$.

D-F. NAM (D), NA (E), and NAAD (F) labeling in the lumen and tissues of mice orally gavaged with mixture of unlabeled NR at a dose of $600 \mathrm{mg} / \mathrm{kg}$ body weight for $3 \mathrm{~h} . \mathrm{n}=4-5$ mice per treatment group.

G. Serum NAM levels in mice treated as in D. 


\section{References}

1. Cantó, C. et al. The NAD+precursor nicotinamide riboside enhances oxidative metabolism and protects against high-fat diet-induced obesity. Cell Metab. (2012). doi:10.1016/j.cmet.2012.04.022

2. Gardell, S. J. et al. Boosting NAD+ with a small molecule that activates NAMPT. Nat. Commun. 10, (2019).

3. Mukhopadhyay, P. et al. PARP inhibition protects against alcoholic and non-alcoholic steatohepatitis. J. Hepatol. 66, (2017).

4. Tarragó, M. G. et al. A Potent and Specific CD38 Inhibitor Ameliorates Age-Related Metabolic Dysfunction by Reversing Tissue NAD+ Decline. Cell Metab. (2018). doi:10.1016/j.cmet.2018.03.016

5. Yoshino, J., Mills, K. F., Yoon, M. J. \& Imai, S. I. Nicotinamide mononucleotide, a key NAD + intermediate, treats the pathophysiology of diet- and age-induced diabetes in mice. Cell Metab. (2011). doi:10.1016/j.cmet.2011.08.014

6. Yoshino, M. et al. Nicotinamide mononucleotide increases muscle insulin sensitivity in prediabetic women. Science 9985, 1-13 (2021).

7. Pirinen, E. et al. Niacin Cures Systemic NAD+ Deficiency and Improves Muscle Performance in Adult-Onset Mitochondrial Myopathy. Cell Metab. 31, (2020).

8. Elhassan, Y. S. et al. Nicotinamide Riboside Augments the Aged Human Skeletal Muscle NAD+ Metabolome and Induces Transcriptomic and Anti-inflammatory Signatures. Cell Rep. (2019). doi:10.1016/j.celrep.2019.07.043

9. Remie, C. M. E. et al. Nicotinamide riboside supplementation alters body composition and skeletal muscle acetylcarnitine concentrations in healthy obese humans. Am. J. Clin. Nutr. (2020). doi:10.1093/ajcn/nqaa072

10. Dollerup, O. L. et al. A randomized placebo-controlled clinical trial of nicotinamide riboside in obese men: Safety, insulin-sensitivity, and lipid-mobilizing effects. Am. J. Clin. Nutr. (2018). doi:10.1093/ajcn/nqy132

11. Sommer, F. \& Bäckhed, F. The gut microbiota-masters of host development and physiology. Nature Reviews Microbiology (2013). doi:10.1038/nrmicro2974

12. Martens, E. C., Chiang, H. C. \& Gordon, J. I. Mucosal Glycan Foraging Enhances Fitness and Transmission of a Saccharolytic Human Gut Bacterial Symbiont. Cell Host Microbe 4, (2008).

13. Desai, M. S. et al. A Dietary Fiber-Deprived Gut Microbiota Degrades the Colonic Mucus Barrier and Enhances Pathogen Susceptibility. Cell 167, (2016).

14. Pickard, J. M. et al. Rapid fucosylation of intestinal epithelium sustains host-commensal symbiosis in sickness. Nature 514, (2014).

15. Sonnenburg, J. L. et al. Glycan foraging in vivo by an intestine-adapted bacterial symbiont. Science (80-. ). 307, (2005).

16. Sonnenburg, E. D. \& Sonnenburg, J. L. Starving our microbial self: The deleterious consequences of a diet deficient in microbiota-accessible carbohydrates. Cell Metabolism 20, (2014).

17. Salyers, A. A., West, S. E. H., Vercellotti, J. R. \& Wilkins, T. D. Fermentation of mucins and plant polysaccharides by anaerobic bacteria from the human colon. Appl. Environ. Microbiol. 34, (1977).

18. Donohoe, D. R. et al. The microbiome and butyrate regulate energy metabolism and autophagy in the mammalian colon. Cell Metab. (2011). doi:10.1016/j.cmet.2011.02.018

19. Bäckhed, F., Manchester, J. K., Semenkovich, C. F. \& Gordon, J. I. Mechanisms underlying the resistance to diet-induced obesity in germ-free mice. Proc. Natl. Acad. Sci. (2007). doi:10.1073/pnas.0605374104 
20. Shats, I. et al. Bacteria Boost Mammalian Host NAD Metabolism by Engaging the Deamidated Biosynthesis Pathway. Cell Metab. (2020). doi:10.1016/j.cmet.2020.02.001

21. Liu, L. et al. Quantitative Analysis of NAD Synthesis-Breakdown Fluxes. Cell Metab. (2018). doi:10.1016/j.cmet.2018.03.018

22. Minhas, P. S. et al. Macrophage de novo NAD+ synthesis specifies immune function in aging and inflammation. Nat. Immunol. (2019). doi:10.1038/s41590-018-0255-3

23. Zhang, J. et al. Switch of NAD Salvage to de novo Biosynthesis Sustains SIRT1-RelBDependent Inflammatory Tolerance. Front. Immunol. 10, (2019).

24. Zapata-Pérez, R. et al. Reduced nicotinamide mononucleotide is a new and potent nad+ precursor in mammalian cells and mice. FASEB J. 35, (2021).

25. Yang, Y., Zhang, N., Zhang, G. \& Sauve, A. A. NRH salvage and conversion to NAD+ requires $\mathrm{NRH}$ kinase activity by adenosine kinase. Nat. Metab. (2020).

doi:10.1038/s42255-020-0194-9

26. Giroud-Gerbetant, J. et al. A reduced form of nicotinamide riboside defines a new path for NAD+ biosynthesis and acts as an orally bioavailable NAD+ precursor. Mol. Metab. (2019). doi:10.1016/j.molmet.2019.09.013

27. Gazzaniga, F., Stebbins, R., Chang, S. Z., McPeek, M. A. \& Brenner, C. Microbial NAD Metabolism: Lessons from Comparative Genomics. Microbiol. Mol. Biol. Rev. (2009). doi:10.1128/mmbr.00042-08

28. Magnúsdóttir, S., Ravcheev, D., De Crécy-Lagard, V. \& Thiele, I. Systematic genome assessment of B-vitamin biosynthesis suggests cooperation among gut microbes. Front. Genet. 6, (2015).

29. Belenky, P. et al. Nicotinamide Riboside Promotes Sir2 Silencing and Extends Lifespan via Nrk and Urh1/Pnp1/Meu1 Pathways to NAD+. Cell 129, (2007).

30. Tempel, W. et al. Nicotinamide riboside kinase structures reveal new pathways to NAD +. PLOS Biol. 5, (2007).

31. Kurnasov, O. et al. NAD Biosynthesis: Identification of the Tryptophan to Quinolinate Pathway in Bacteria. Chem. Biol. 10, (2003).

32. Bockwoldt, M. et al. Identification of evolutionary and kinetic drivers of NAD-dependent signaling. Proc. Natl. Acad. Sci. U. S. A. (2019). doi:10.1073/pnas.1902346116

33. Pellizzon, M. A. \& Ricci, M. R. The common use of improper control diets in diet-induced metabolic disease research confounds data interpretation: The fiber factor. Nutrition and Metabolism 15, (2018).

34. van der Hee, B. \& Wells, J. M. Microbial Regulation of Host Physiology by Short-chain Fatty Acids. Trends in Microbiology (2021). doi:10.1016/j.tim.2021.02.001

35. Kaur, A., Rose, D. J., Rumpagaporn, P., Patterson, J. A. \& Hamaker, B. R. In VitroBatch Fecal Fermentation Comparison of Gas and Short-Chain Fatty Acid Production Using 'Slowly Fermentable' Dietary Fibers. J. Food Sci. 76, (2011).

36. Jang, C. et al. The Small Intestine Converts Dietary Fructose into Glucose and Organic Acids. Cell Metab. 27, 351-361.e3 (2018).

37. Henderson, L. M. \& Gross, C. J. Metabolism of niacin and niacinamide in perfused rat intestine. J. Nutr. (1979). doi:10.1093/jn/109.4.654

38. Henderson, L. M. \& Gross, C. J. Transport of niacin and niacinamide in perfused rat intestine. J. Nutr. (1979). doi:10.1093/jn/109.4.646

39. McReynolds, M. R. et al. NAD+ flux is maintained in aged mice despite lower tissue concentrations. Cell Syst. (2021). doi:10.1016/j.cels.2021.09.001

40. Yoshino, J., Baur, J. A. \& Imai, S. NAD + Intermediates: The Biology and Therapeutic Potential of NMN and NR. Cell Metab. 2, (2017).

41. Frederick, D. W. et al. Loss of NAD Homeostasis Leads to Progressive and Reversible Degeneration of Skeletal Muscle. Cell Metab. 24, 269-282 (2016).

42. Carlson, L. A., Orö, L. \& östman, J. EFFECT OF A SINGLE DOSE OF NICOTINIC ACID 
ON PLASMA LIPIDS IN PATIENTS WITH HYPERLIPOPROTEINEMIA. Acta Med. Scand. 183, (1968).

43. Reiche, I. et al. Pharmacokinetics and dose recommendations of Niaspan® in chronic kidney disease and dialysis patients. Nephrol. Dial. Transplant. 26, (2011).

44. Menon, R. M., Tolbert, D. \& Cefali, E. The comparative bioavailability of an extendedrelease niacin and lovastatin fixed dose combination tablet versus extended-release niacin tablet, lovastatin tablet and a combination of extended-release niacin tablet and lovastatin tablet. Biopharm. Drug Dispos. 28, (2007).

45. Soga, T. et al. Molecular identification of nicotinic acid receptor. Biochem. Biophys. Res. Commun. 303, (2003).

46. Tunaru, S. et al. PUMA-G and HM74 are receptors for nicotinic acid and mediate its antilipolytic effect. Nat. Med. (2003). doi:10.1038/nm824

47. Wise, A. et al. Molecular identification of high and low affinity receptors for nicotinic acid. J. Biol. Chem. 278, (2003).

48. Trammell, S. A. J. et al. Nicotinamide riboside is uniquely and orally bioavailable in mice and humans. Nat. Commun. 7, (2016).

49. Kim, L. J. et al. Nicotinamide mononucleotide (NMN) deamidation by the gut microbiome and evidence for indirect upregulation of the NAD+ metabolome. bioRxiv (2020). doi:10.1101/2020.09.10.289561

50. French, J. B. et al. Characterization of nicotinamidases: Steady state kinetic parameters, classwide inhibition by nicotinaldehydes, and catalytic mechanism. Biochemistry (2010). doi:10.1021/bi1012518

51. Salyers, A. A., Vercellotti, J. R., West, S. E. H. \& Wilkins, T. D. Fermentation of mucin and plant polysaccharides by strains of Bacteroides from the human colon. Appl. Environ. Microbiol. 33, (1977).

52. Stewart, G. S. \& Smith, C. P. Urea nitrogen salvage mechanisms and their relevance to ruminants, non-ruminants and man. Nutr. Res. Rev. 18, (2005).

53. Ni, J. et al. A role for bacterial urease in gut dysbiosis and Crohn's disease. Sci. Transl. Med. 9, (2017).

54. Fuller, M. F. \& Reeds, P. J. Nitrogen cycling in the gut. Annual Review of Nutrition 18, (1998).

55. Scheiman, J. et al. Meta-omics analysis of elite athletes identifies a performanceenhancing microbe that functions via lactate metabolism. Nat. Med. 25, (2019).

56. Ding, J. W., Andersson, R., Soltesz, V., Willén, R. \& Bengmark, S. The role of bile and bile acids in bacterial translocation in obstructive jaundice in rats. Eur. Surg. Res. 25, (1993).

57. Lorenzo-Zúñiga, V. et al. Oral bile acids reduce bacterial overgrowth, bacterial translocation, and endotoxemia in cirrhotic rats. Hepatology 37, (2003).

58. BORGSTROM, B., DAHLQVIST, A., LUNDH, G. \& SJOVALL, J. Studies of intestinal digestion and absorption in the human. J. Clin. Invest. 36, (1957).

59. Jacobson, E. L., Dame, A. J., Pyrek, J. S. \& Jacobson, M. K. Evaluating the role of niacin in human carcinogenesis. Biochimie 77, (1995).

60. Hara, N. et al. Elevation of cellular NAD levels by nicotinic acid and involvement of nicotinic acid phosphoribosyltransferase in human cells. J. Biol. Chem. (2007). doi:10.1074/jbc.M610357200

61. Zamporlini, F. et al. Novel assay for simultaneous measurement of pyridine mononucleotides synthesizing activities allows dissection of the NAD + biosynthetic machinery in mammalian cells. FEBS J. 281, (2014).

62. Li, X. Q. et al. nAMPT and NAPRT, key enzymes in nad salvage synthesis pathway, are of negative prognostic value in colorectal cancer. Front. Oncol. 9, (2019).

63. Chowdhry, S. et al. NAD metabolic dependency in cancer is shaped by gene 
amplification and enhancer remodelling. Nature (2019). doi:10.1038/s41586-019-1150-2

64. Piacente, F. et al. Nicotinic acid phosphoribosyltransferase regulates cancer cell metabolism, susceptibility to NAMPT inhibitors, and DNA repair. Cancer Res. (2017). doi:10.1158/0008-5472.CAN-16-3079

65. Elliott, G. C. \& Rechsteiner, M. C. Evidence for a physiologically active nicotinamide phosphoribosyl transferase in cultured human fibroblasts. Biochem. Biophys. Res. Commun. 104, (1982).

66. Gaut, Z. N. \& Solomon, H. M. Inhibition of nicotinate phosphoribosyltransferase in human platelet lysate by nicotinic acid analogs. Biochem. Pharmacol. 20, (1971).

67. Hillyard, D., Rechsteiner, M. C. \& Olivera, B. M. Pyridine nucleotide metabolism in mammalian cells in culture. J. Cell. Physiol. 82, (1973).

68. Benyó, Z. et al. GPR109A (PUMA-G/HM74A) mediates nicotinic acid-induced flushing. J. Clin. Invest. (2005). doi:10.1172/JCl23626

69. Romani, M., Hofer, D. C., Katsyuba, E. \& Auwerx, J. Niacin: An old lipid drug in a new NAD+ dress. Journal of Lipid Research 60, (2019).

70. $\mathrm{Hu}, \mathrm{M}$. et al. Liver fat reduction with niacin is influenced by DGAT-2 polymorphisms in hypertriglyceridemic patients. J. Lipid Res. 53, (2012).

71. Ganji, S. H. et al. Niacin noncompetitively inhibits DGAT2 but not DGAT1 activity in HepG2 cells. J. Lipid Res. 45, (2004).

72. Nzoughet, J. K. et al. Nicotinamide deficiency in primary open-angle glaucoma. Investig. Ophthalmol. Vis. Sci. 60, (2019).

73. Odum, E. P. \& Wakwe, V. C. Plasma concentrations of water-soluble vitamins in metabolic syndrome subjects. Niger. J. Clin. Pract. 15, (2012).

74. Ibrahim, G. R. et al. Significantly Elevated Levels of Plasma Nicotinamide, Pyridoxal, and Pyridoxamine Phosphate Levels in Obese Emirati Population: A Cross-Sectional Study. Molecules 25, (2020).

75. Daïen, C. I., Pinget, G. V., Tan, J. K. \& Macia, L. Detrimental impact of microbiotaaccessible carbohydrate-deprived diet on gut and immune homeostasis: An overview. Frontiers in Immunology 8, (2017).

76. Tan, J. et al. The Role of Short-Chain Fatty Acids in Health and Disease. in Advances in Immunology 121, (2014).

77. Zhao, S. et al. Dietary fructose feeds hepatic lipogenesis via microbiota-derived acetate. Nature 579, (2020).

78. Makarov, M. V., Harris, N. W., Rodrigues, M. \& Migaud, M. E. Scalable syntheses of traceable ribosylated NAD+ precursors. Org. Biomol. Chem. (2019). doi:10.1039/c9ob01981b

79. Wang, L. et al. Peak Annotation and Verification Engine for Untargeted LC-MS Metabolomics. Anal. Chem. (2019). doi:10.1021/acs.analchem.8b03132

80. Adusumilli, R. \& Mallick, P. Data conversion with proteoWizard msConvert. in Methods in Molecular Biology (2017). doi:10.1007/978-1-4939-6747-6_23 
A (which was not certified by peer review) is the author/funder, who has granted bioRxiv a license to display the preprint in perpetuity. It is made Microbial NAD biosynthetic pathways
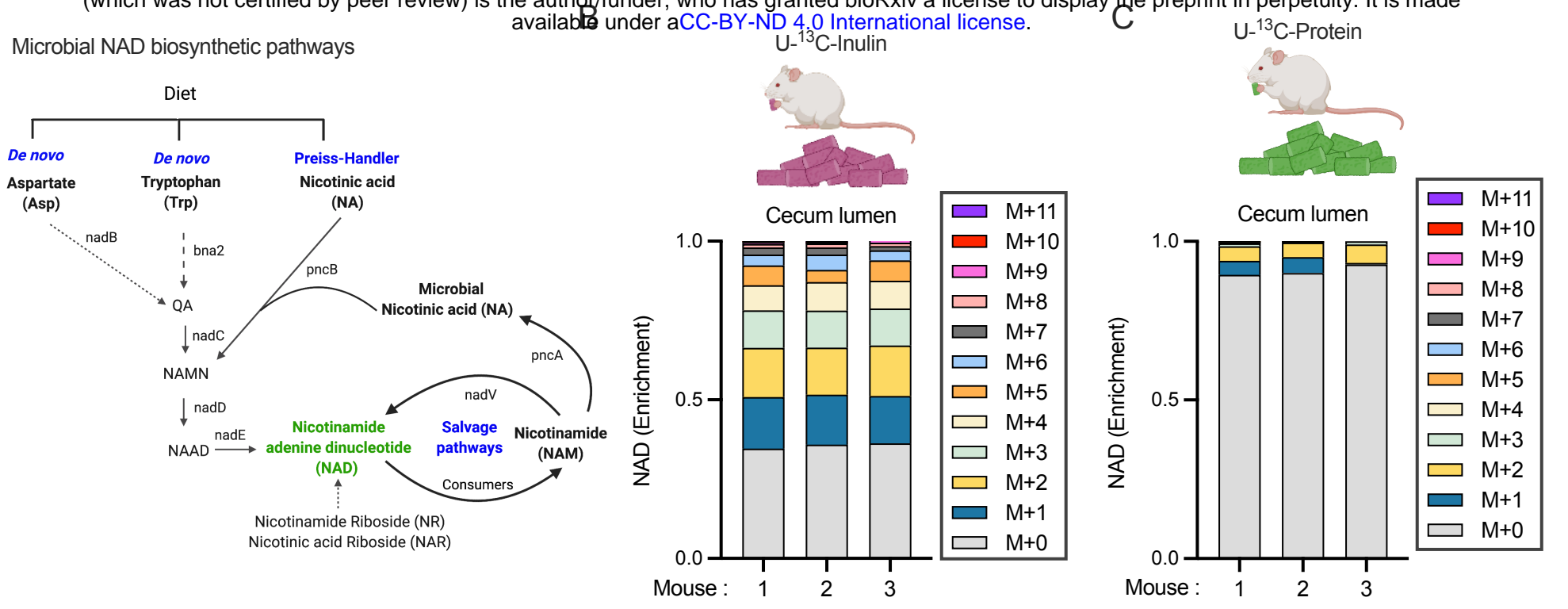

D

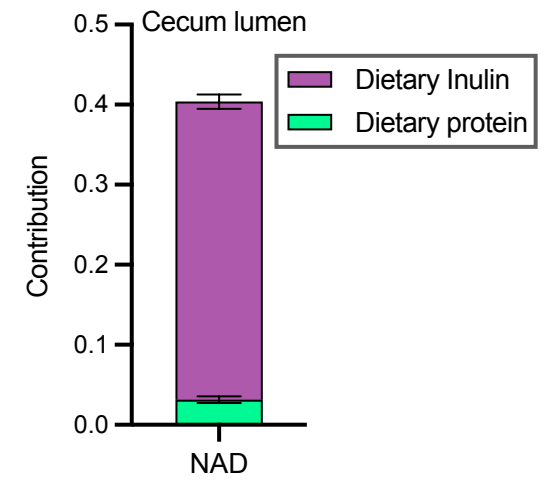

E

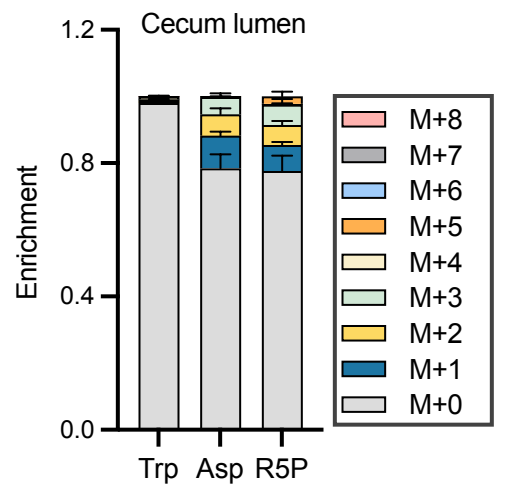

F

(1)

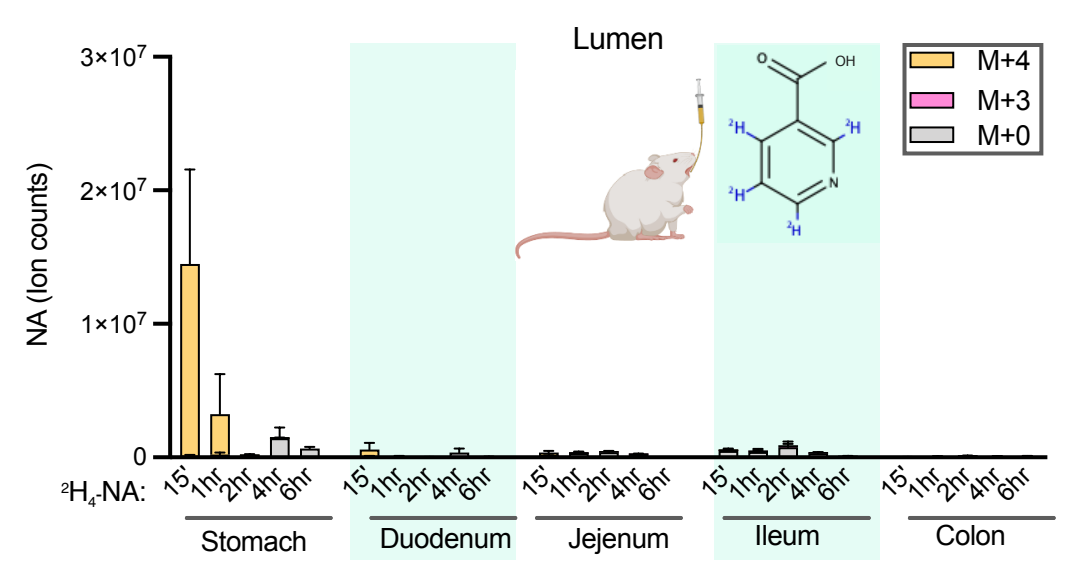

$\mathrm{H}$

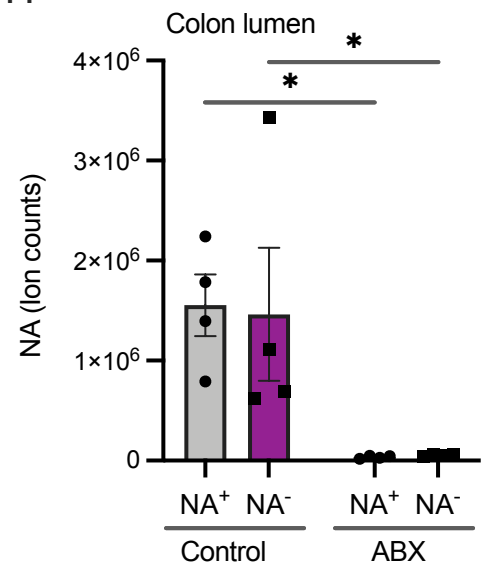

I

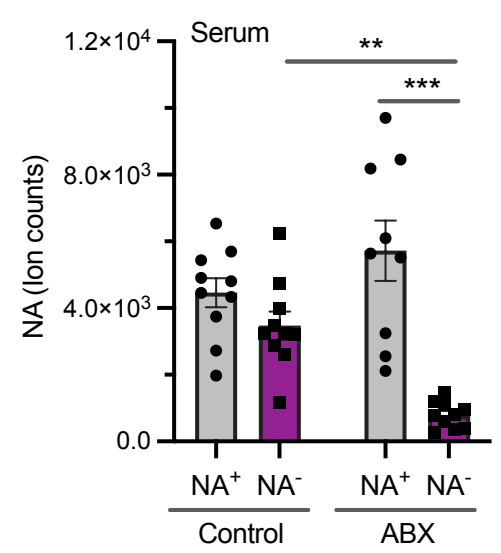

G

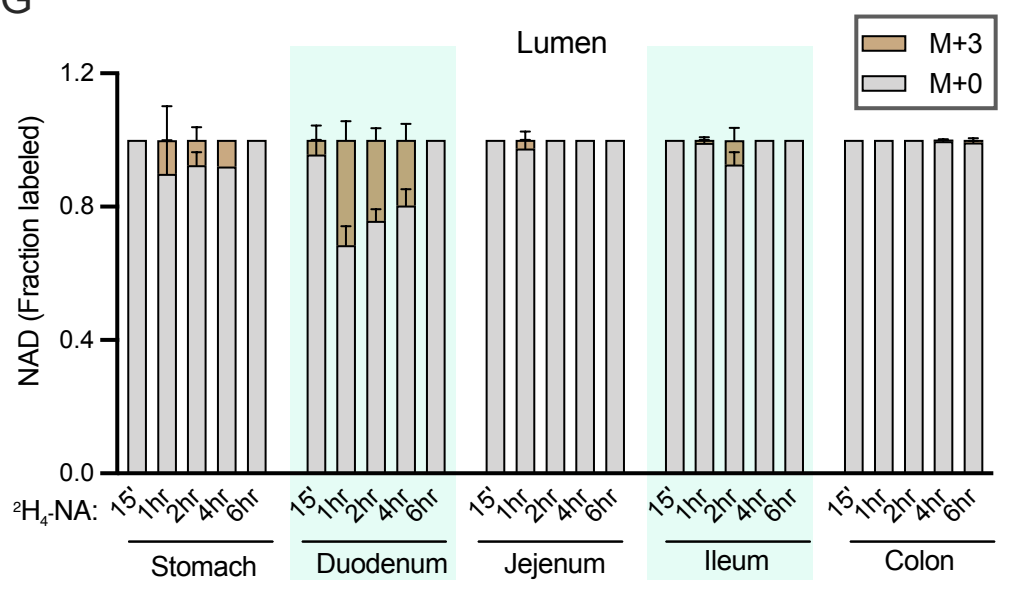

J

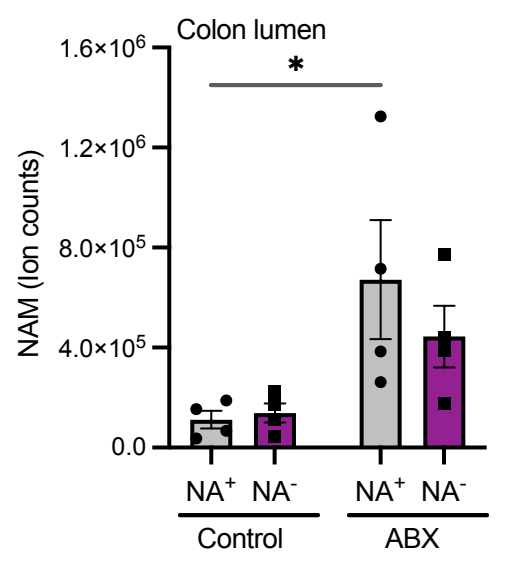

K

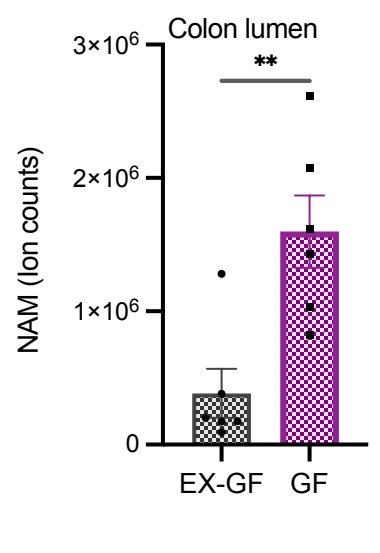


Figure 1. The majority of microbial NAD synthesis is not accounted for by dietary precursors.

A. Different pathways used for NAD biosynthesis in microbes.

B. Enrichment of carbon labeled NAD in the cecal lumen of mice fed with $U-{ }^{13} \mathrm{C}$-inulin for $24 \mathrm{~h} . \mathrm{n}=3$ mice per group.

C. Enrichment of carbon labeled NAD in the cecal lumen of mice fed with $U-{ }^{13} \mathrm{C}$-protein for $24 \mathrm{~h}$. $n=3$ mice per group.

D. Contribution of $U-{ }^{13} \mathrm{C}$-protein and $U-{ }^{13} \mathrm{C}$-inulin to NAD synthesis in the cecal lumen of mice treated as in $B$ and $C$.

E. Enrichment of carbon labeled tryptophan, aspartate, and ribose phosphate in cecal lumen of mice treated as in $\mathrm{B}$.

F. Labeled and unlabeled NA content and fraction NAD (B) in the gut lumen after oral gavage of 1.96 $\mu$ moles of $\left[2,4,5,6-{ }^{2} \mathrm{H}\right]-\mathrm{NA}$, equivalent to one-third daily dietary nicotinic acid intake.

G. Fraction labeled NAD in the gut lumen of mice treated as in F.

$\mathrm{H}$. NA content in the colonic lumen of conventional mice fed diet with $\left(N \mathrm{~A}^{+}\right)$or without nicotinic acid $\left(N A^{-}\right)$that were on drinking water or antibiotics cocktail $(A B X) . n=4$ per group.

I. NA content in the serum of mice treated as in $\mathrm{H}$. $\mathrm{n}=9-10$ mice per group.

J. NAM content in the colonic lumen of mice treated as in $\mathrm{H}$. $\mathrm{n}=4$ per group.

K. Abundance of NAM in the colonic lumen of germ-free (GF) and germ-free mice colonized with microbiota from specific pathogen free mice (Ex-GF). $n=4$ per group. 
bioRxiv preprint doi: https://doi.org/10.1101/2021.11.15.468729; this version posted November 19,2021 . The copyright holder for this preprint (which was not certified by peer review) is the author/funder, who has granted bioRxiv a license to display the preprint in perpetuity. It is made available under aCC-BY-ND 4.0 International license.

A

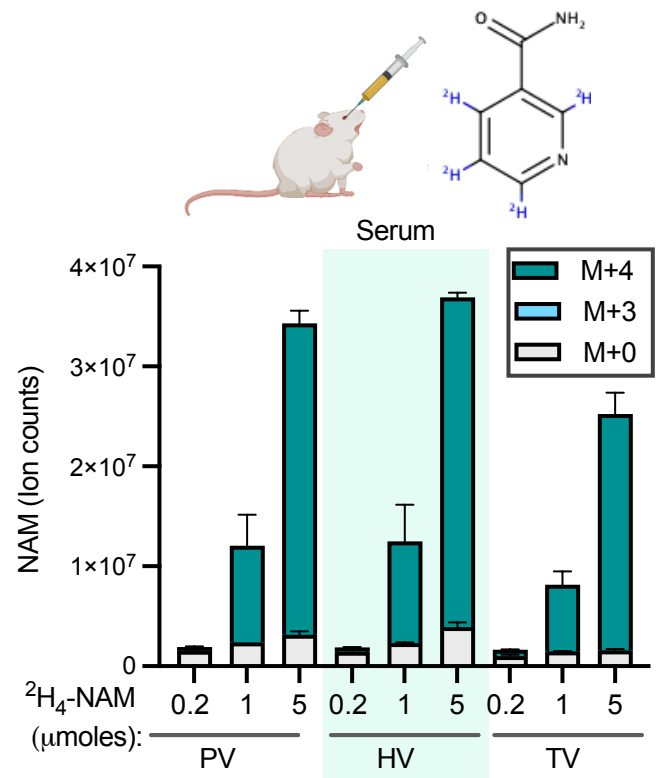

C

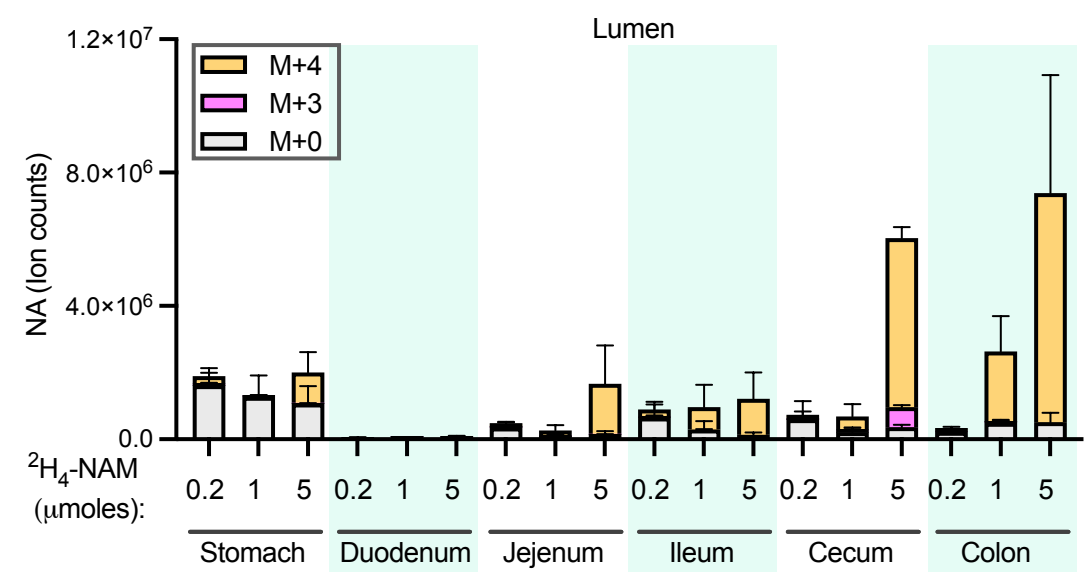

$\mathrm{E}$

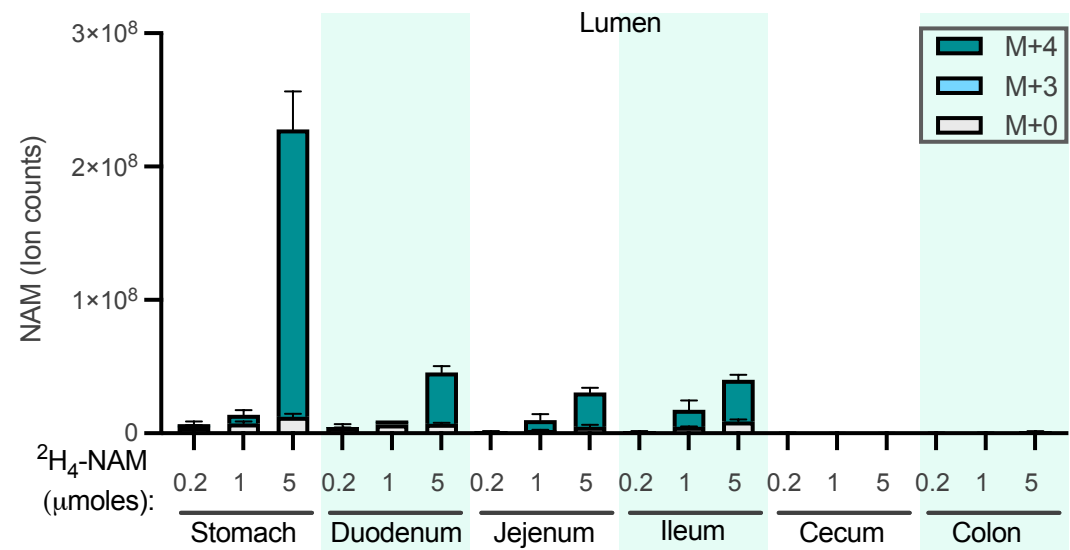

D

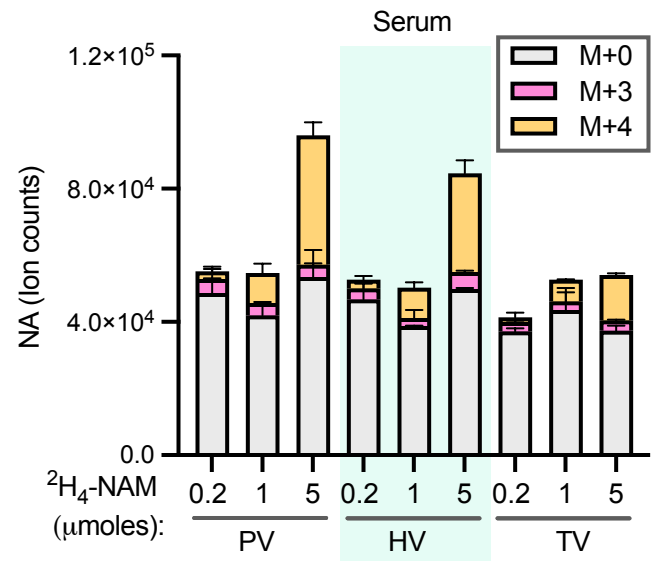

F

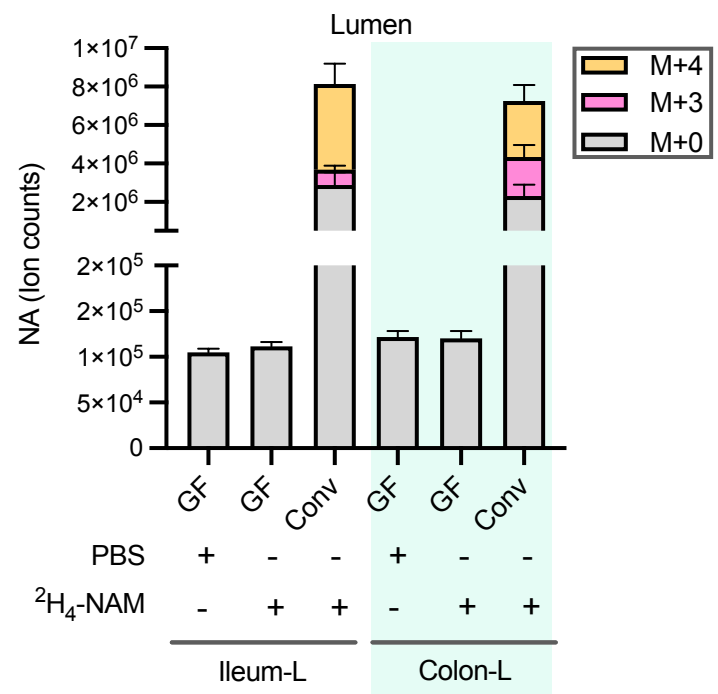


Figure 2. Circulating NAM enters the gut lumen and supports microbial NAD biosynthesis.

A. NAM levels in the serum samples collected from portal (PV), hepatic (HV) and tail vein (TV) 15 min after retro-orbital injection of different doses of [2,4,5,6-2H]-NAM. $n=2-3$ mice per group.

B. Labeled NAM detected in the lumen samples collected from mice treated as in A.

C. Labeled and unlabeled NA detected in the luminal samples collected from mice treated as in A.

D. Labeled and unlabeled NA detected in the serum samples collected from mice treated as in A.

E. Labeled and unlabeled NAM in luminal samples collected from germ-free (GF) and conventional (Conv) mice retro-orbitally injected with 5 umoles of [2,4,5,6-2H]-NAM and sacrificed after $2 \mathrm{~h} . \mathrm{n}=4$ mice per group.

F. Labeled and unlabeled NA in the luminal samples collected from mice treated as in $\mathrm{E}$. 


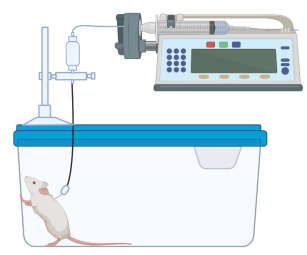<smiles>NC(=O)c1ccccc1</smiles>
available under aCC-BY-ND 4.0 International license.

\section{${ }^{2} \mathrm{H}_{4}$-NAM (hr): $2 \mathrm{~h} \quad 5 \mathrm{~h} 12 \mathrm{~h} 18 \mathrm{~h} 24 \mathrm{~h}$}

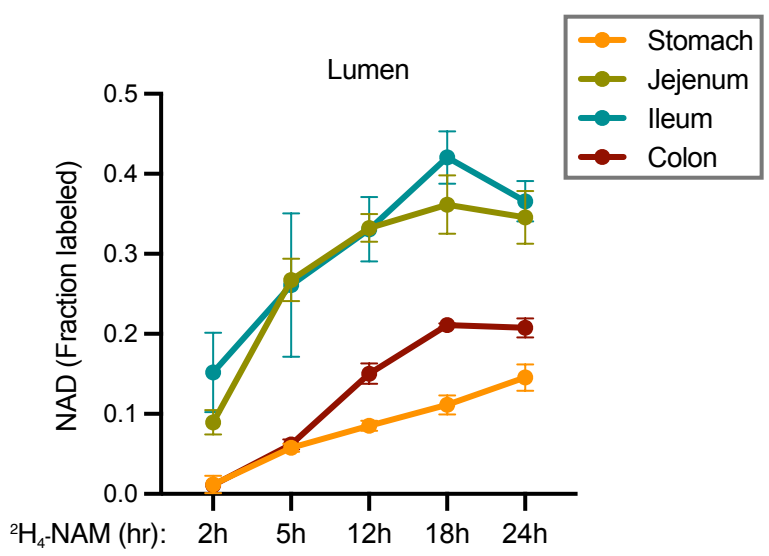

C

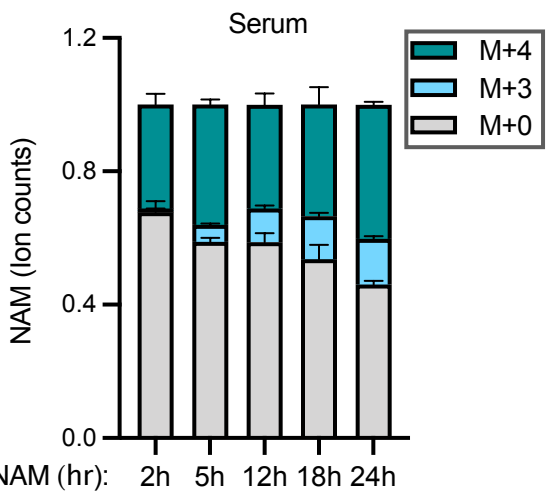

D

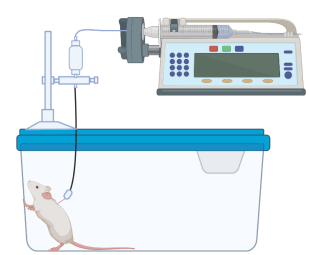<smiles>NC(=O)c1ccccc1</smiles>

$E$
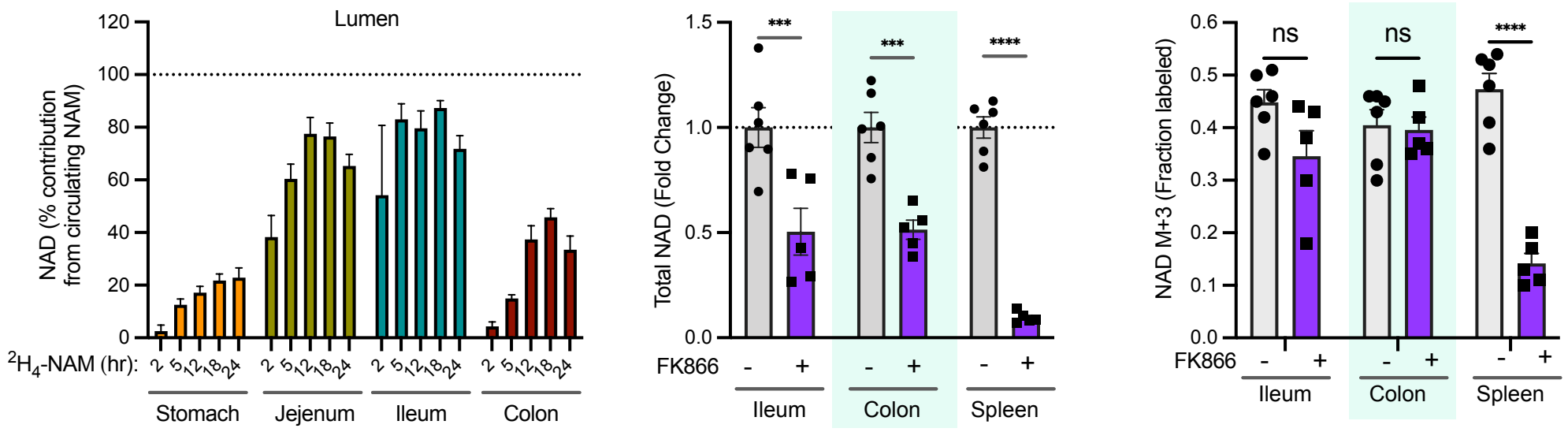

$\mathrm{F}$

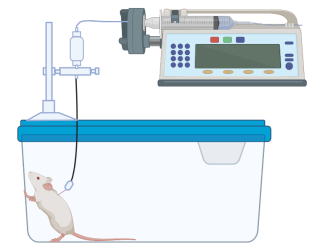<smiles>NC(=O)c1cnccc1I</smiles>
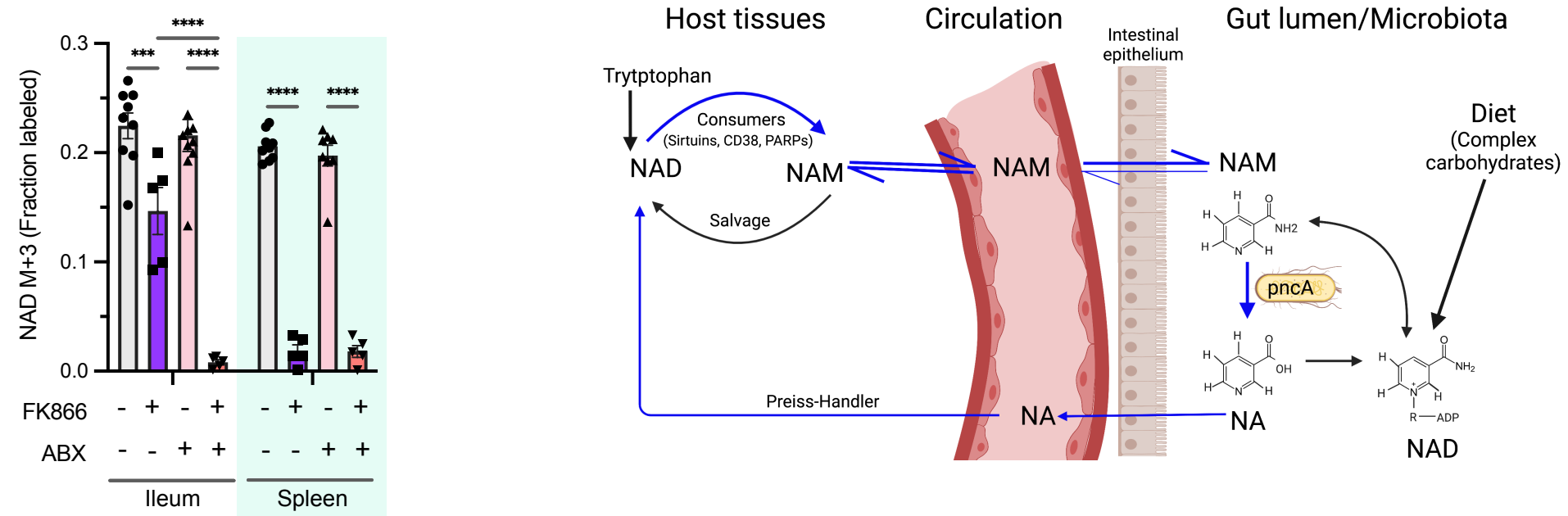
Figure 3. Vitamin B3 cycles between host and microbiome.

A. Fraction labeling of nicotinamide in the serum of mice infused with $4 \mathrm{mM}\left[2,4,5,6-{ }^{2} \mathrm{H}\right]-\mathrm{NAM}$ for different time points. $\mathrm{n}=2-4$ mice per group.

B. Fraction labeled NAD in the luminal content of mice infused as in $A$.

C. Percent contribution of circulating NAM to NAD synthesis in different parts of the gastrointestinal tract.

D. Relative levels of total NAD in mice intraperitoneally injected with vehicle or FK866 and infused with [2,4,5,6-2H]-NAM for 24h. $\mathrm{n}=5-6$ mice per treatment group.

E. Fraction labeled NAD in mice treated as in D.

Data for spleen in D and E was previously reported in McReynolds et al. Cell system, 2021.

F. Fraction labeled NAD in tissues collected from control and antibiotics (ABX) treated mice intraperitoneally injected with vehicle or FK866 and infused with [2,4,5,6-2 H]-NAM for 5h. n=3-5 mice per treatment group.

G. Model showing a vitamin B3 cycle between host and microbes. Host-derived NAM in the circulation enters the gut lumen and is deamidated to NA by the microbiome. In turn, host tissues use microbiome-produced NA for synthesis of NAD, which is turned over to release NAM. 
bioRxiv preprint doi: https://doi.org/10.1101/2021.11.15.468729; this version posted November 19, 2021. The copyright holder for this preprint (which was not certified by peer review) is the author/funder, who has granted bioRxiv a license to display the preprint in perpetuity. It is made

A

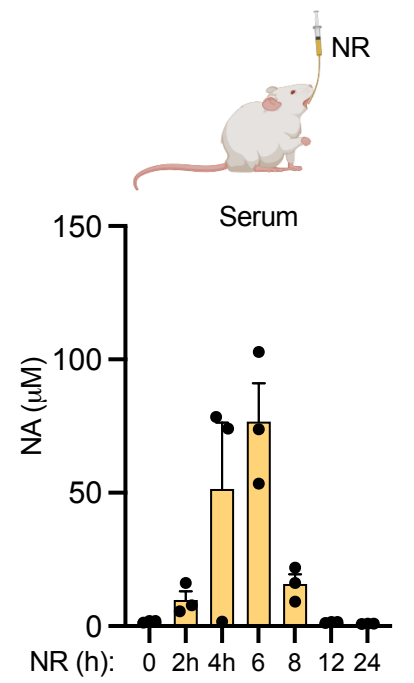

D

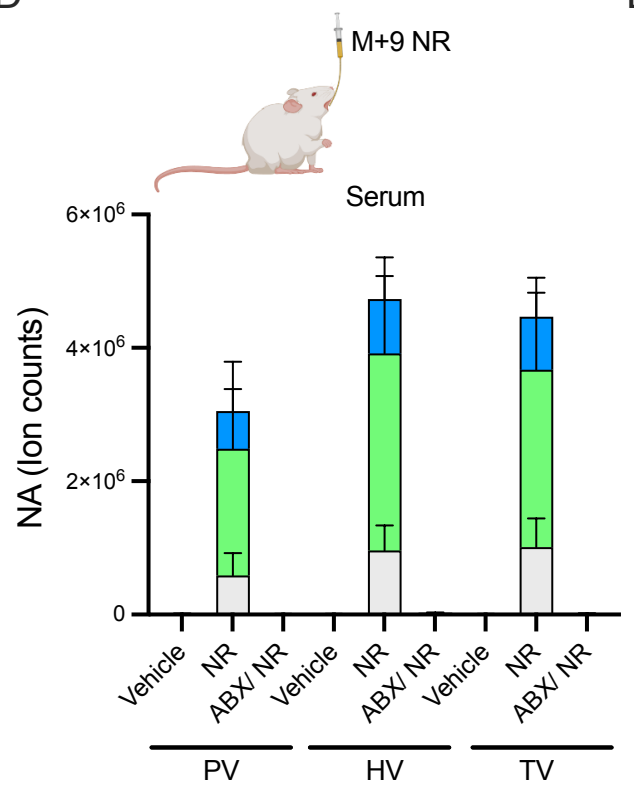

F

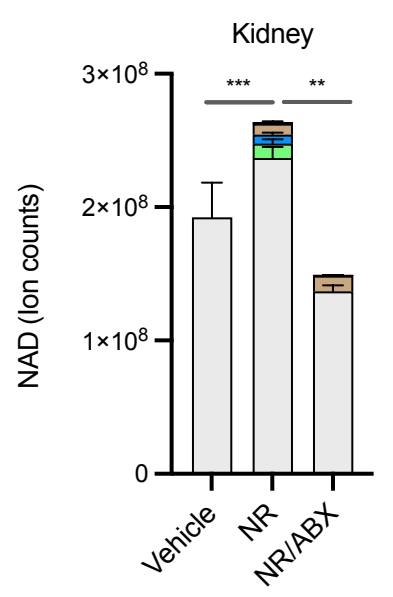

B available under aCC-BY-ND 4.0 International license.

\section{M+9 NR}

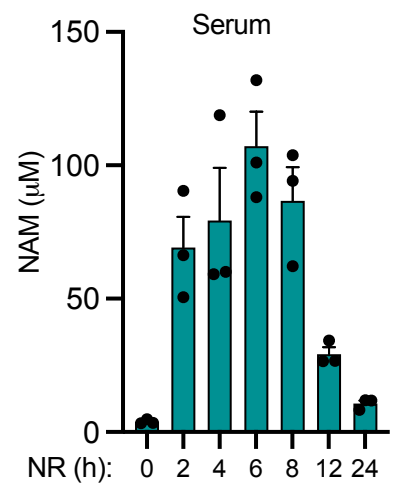

\section{E}

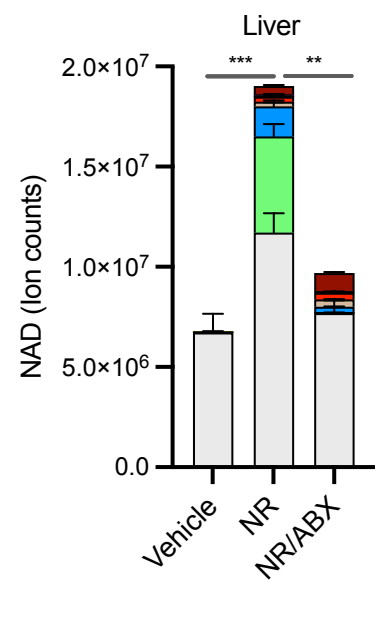

$\mathrm{H}$

G

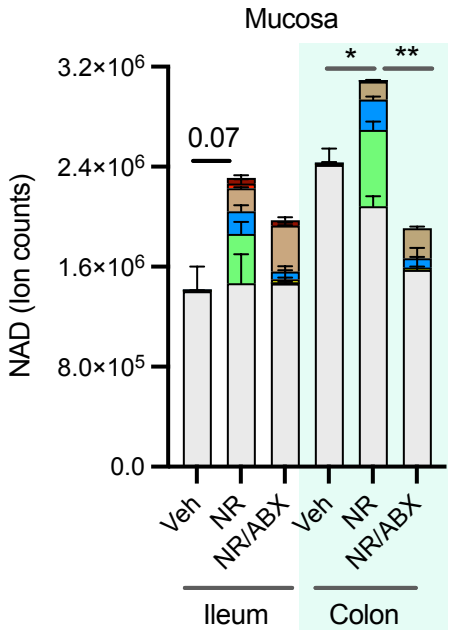

\begin{tabular}{|c|c|c|}
\hline$\square$ & $\mathrm{M}+9 \rightarrow$ & Direct NR uptake and NAD synthesis \\
\hline$\square$ & $M+8$ & \\
\hline$\square$ & $M+7$ & $\begin{array}{l}\text { Deamidation and reamidation of NR } \\
\text { (NAR derivatives) }\end{array}$ \\
\hline 匹 & $M+6$ & \\
\hline & $M+5$ & Cleavage of NR \\
\hline ط & $M+4$ & $\begin{array}{l}\text { Cleavage of NR or turnover of } \\
M+9 \text { NAD }\end{array}$ \\
\hline$\square$ & $M+3$ & \\
\hline$\square$ & $M+2$ & Deamidation and reamidation of NAM \\
\hline$\square$ & $M+1$ & \\
\hline$\square$ & $\mathrm{M}+\mathrm{O} \rightarrow$ & Unlabeled \\
\hline
\end{tabular}
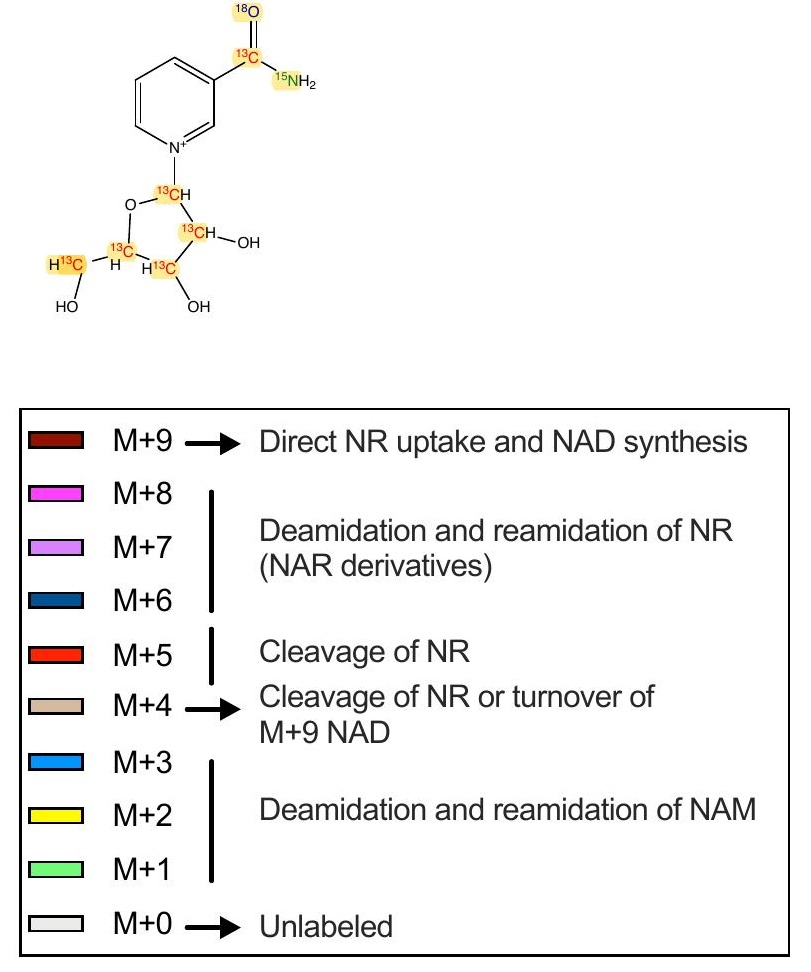

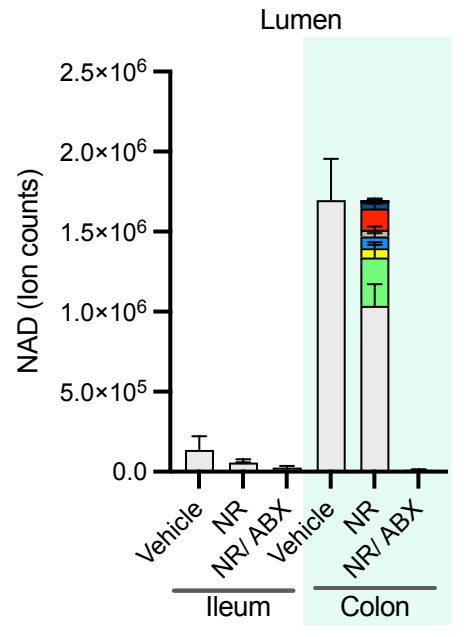


Figure 4. Oral NR supports NAD synthesis in mammalian tissues mainly via conversion to NA.

A. Serum concentration of NA in mice orally gavaged with NR at a dose of $500 \mathrm{mg} / \mathrm{kg}$ body weight $\mathrm{n}=3$ per group.

B. Serum NAM concentration in mice treated as in A.

C. M+9 NR isotopically labeled in the amide group of nicotinamide moiety and ribose ring to establish the molecular fate of NR in host and microbes.

D. Relative level of NA in the serum of control and antibiotics (ABX) treated mice orally gavaged with PBS (vehicle) or NR at a dose of $600 \mathrm{mg} / \mathrm{kg}$ body weight. Serum samples were collected from portal vein $(P V)$, hepatic vein $(H V)$ and tail vein (TV) after $3 \mathrm{~h}$ of treatment $(n=4-5$ per treatment group).

E. NAD isotopologues detected in the liver of mice treated as in D.

F. NAD isomers in the kidney of mice treated as in D.

G. Isotopologues of NAD in the intestinal tissues of mice treated as in D.

$H$. Labeling pattern of NAD in the luminal samples collected from mice treated as in D. 
bioRxiv preprint doi: https://doi.org/10.1101/2021.11.15.468729; this version posted November 19, 2021. The copyright holder for this preprint (which was not certified by peer review) is the author/funder, who has granted bioRxiv a license to display the preprint in perpetuity. It is made

A

E

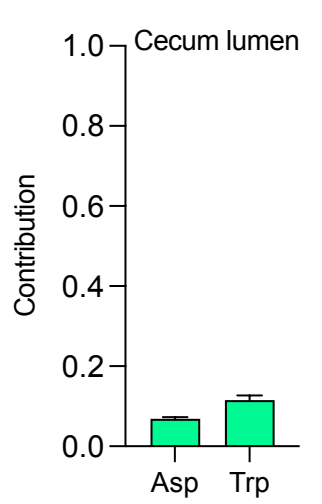

B available under aCC-BY-ND 4.0 International license.
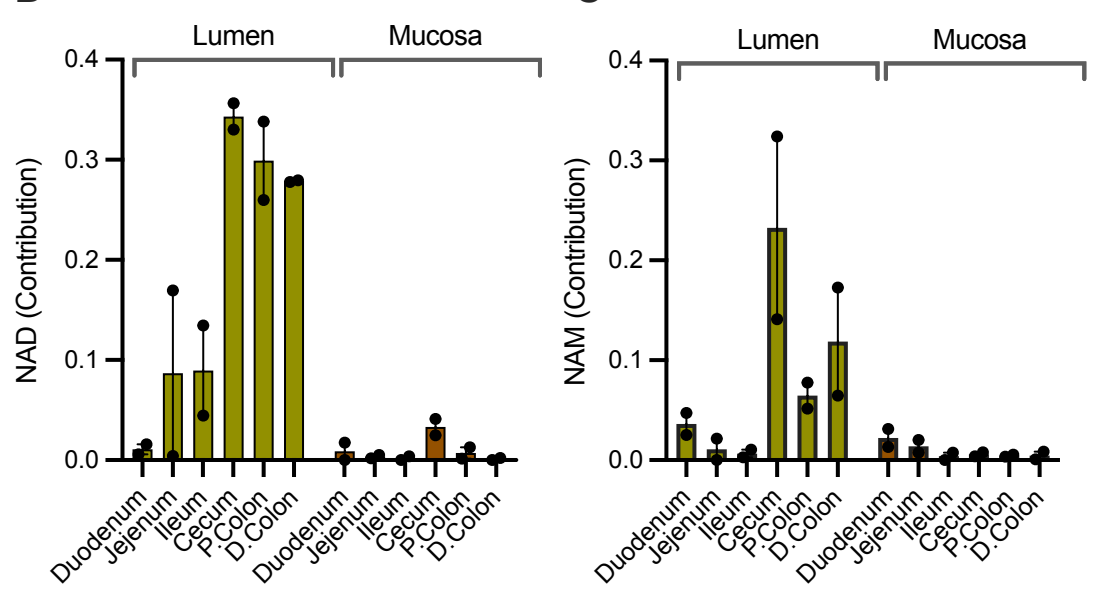

$\mathrm{F}$
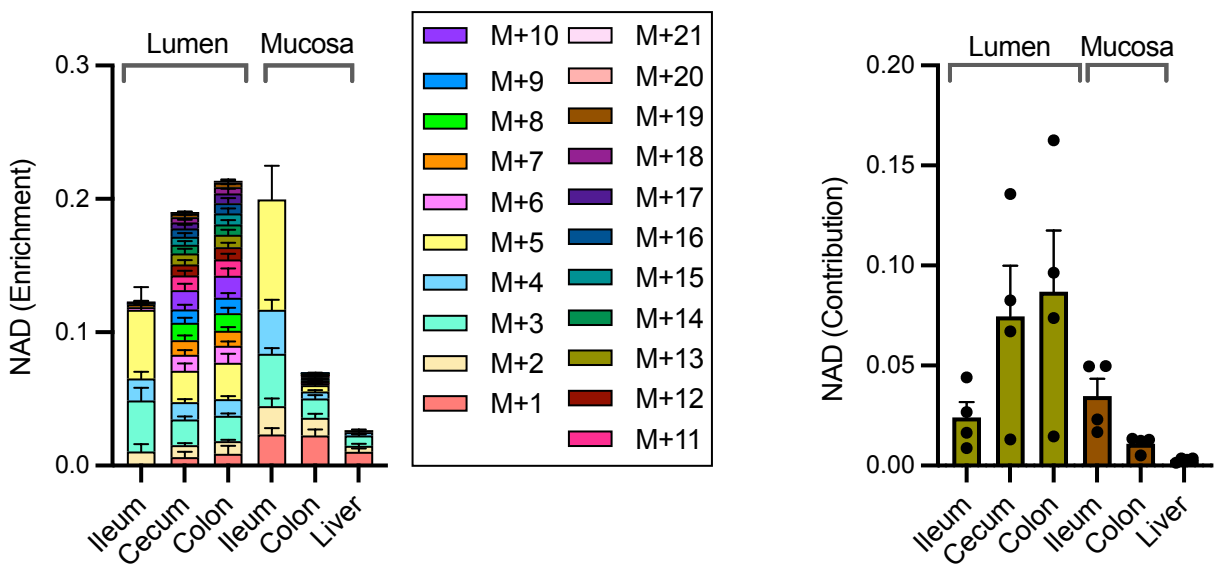

$\mathrm{H}$
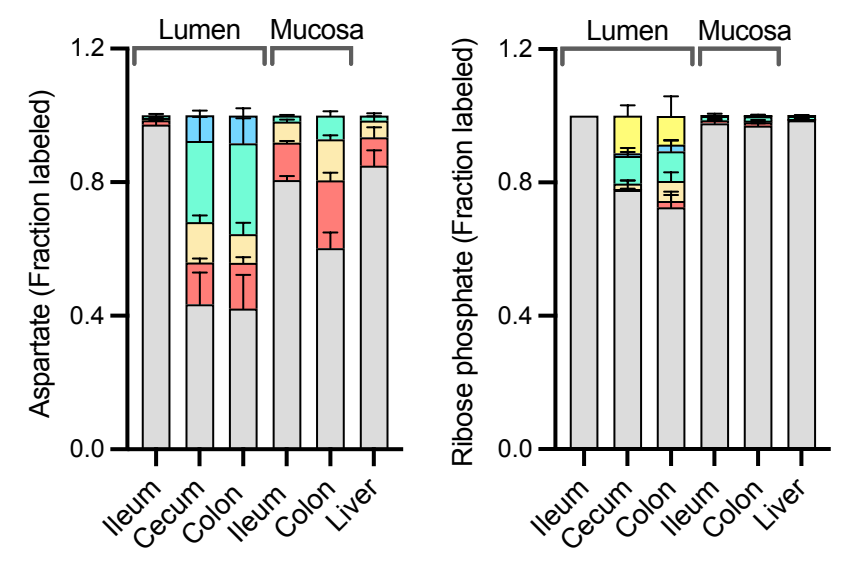

L
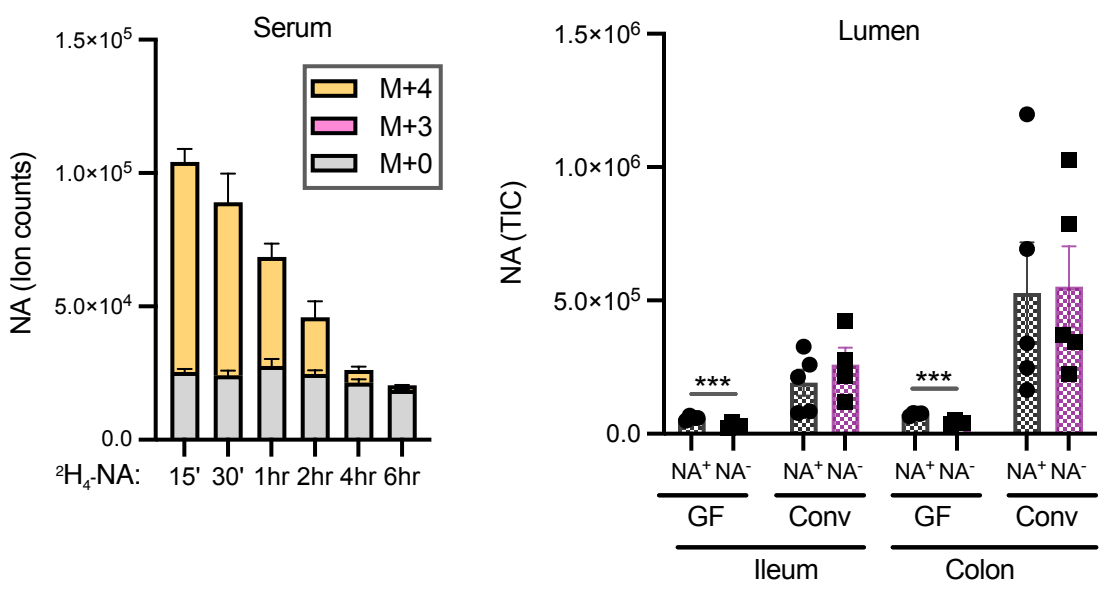

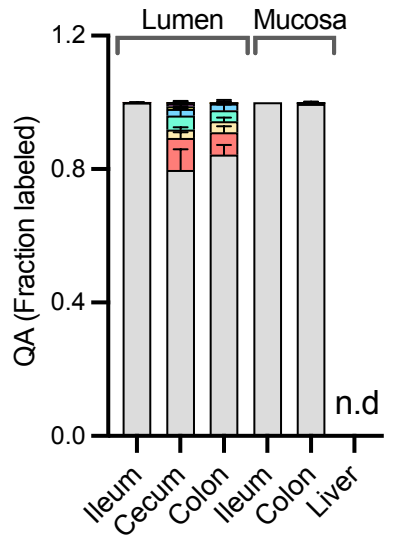

M
${ }^{2} \mathrm{H}_{4}$-NA: 15 ' 30 ' $1 \mathrm{hr} 2 \mathrm{hr} 4 \mathrm{hr} 6 \mathrm{hr}$

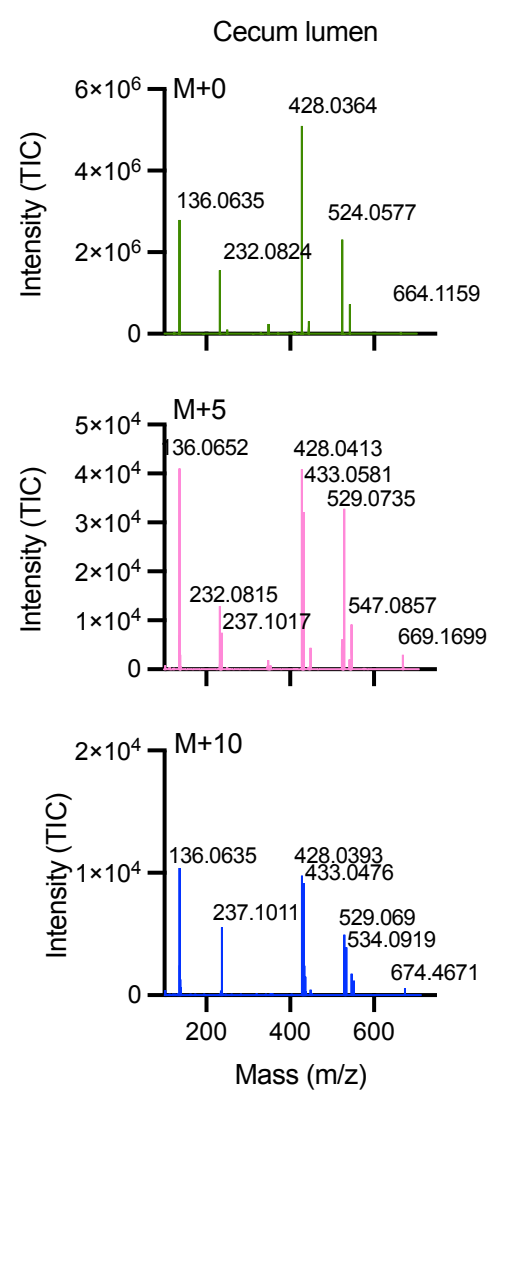

Colon Lumen
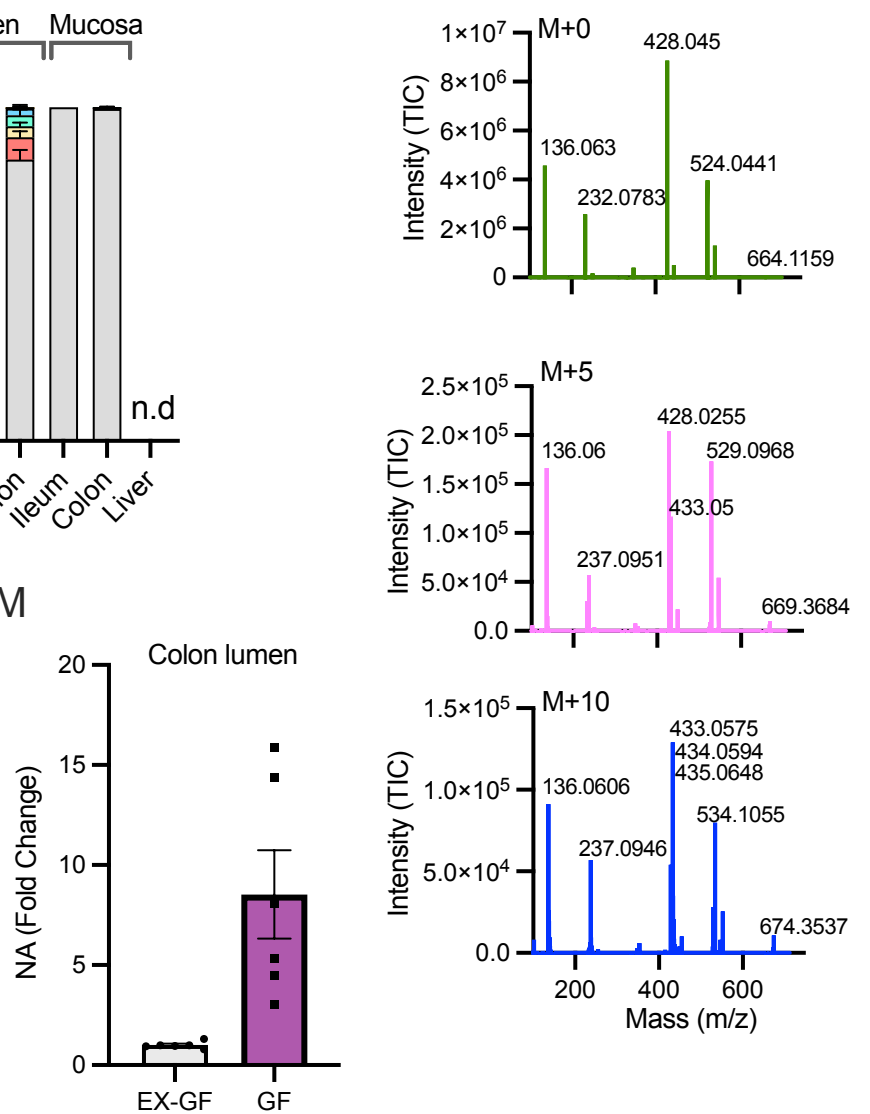


\section{Supplementary Figure 1. Site-specific use of dietary NAD precursors by microbes along the GI tract.}

A. Contribution of $U-{ }^{13} \mathrm{C}$-protein to aspartate and tryptophan levels in the cecum lumen of mice fed with labeled protein diet. $\mathrm{n}=3$ mice.

B. Contribution of $U-{ }^{13} \mathrm{C}$-inulin to NAD synthesis in different parts of gastrointestinal tract of mice fed with labeled protein. $\mathrm{n}=2$ mice.

C. Contribution of $U-{ }^{13} \mathrm{C}$-inulin to nicotinamide in the gut lumen of mice treated as in $\mathrm{B} . \mathrm{n}=2$ mice.

D. $M S^{2}$ fragments of $N A D$ detected in the cecum lumen of mice fed with $U-{ }^{13} \mathrm{C}$-inulin fed as in $\mathrm{B}$.

E-F. Enrichment of NAD labeling $(E)$ and contribution to NAD synthesis $(F)$ in mice orally gavaged with $U-{ }^{13} \mathrm{C}$-fructose for $2 \mathrm{~h}$ at a dose of $2 \mathrm{~g} / \mathrm{kg} . \mathrm{n}=4$ mice.

G-I. Enrichment of aspartate $(\mathrm{G})$ ribose phosphate $(\mathrm{H})$ and quinolinic acid $(\mathrm{I})$ labeling in mice treated as in $\mathrm{E}$.

J. $M S^{2}$ fragments of NAD detected in the colonic lumen of mice treated as in $\mathrm{E}$.

K. Labeled and unlabeled NA in the serum after oral gavage of $1.96 \mu$ moles of $\left[2,4,5,6-{ }^{2} \mathrm{H}\right]-\mathrm{NA} n=2-$ 6.

L. NA content in the lumen of germ free (GF) and conventional (Conv) mice fed diet with (NA ${ }^{+}$) or without nicotinic acid (NA-). $n=4-5$ mice per group.

M. Abundance of NA in the colonic lumen of germ-free (GF) and Ex-germ free (Ex-GF) mice colonized with microbiota from SPF mice. $n=4$ per group. 
A

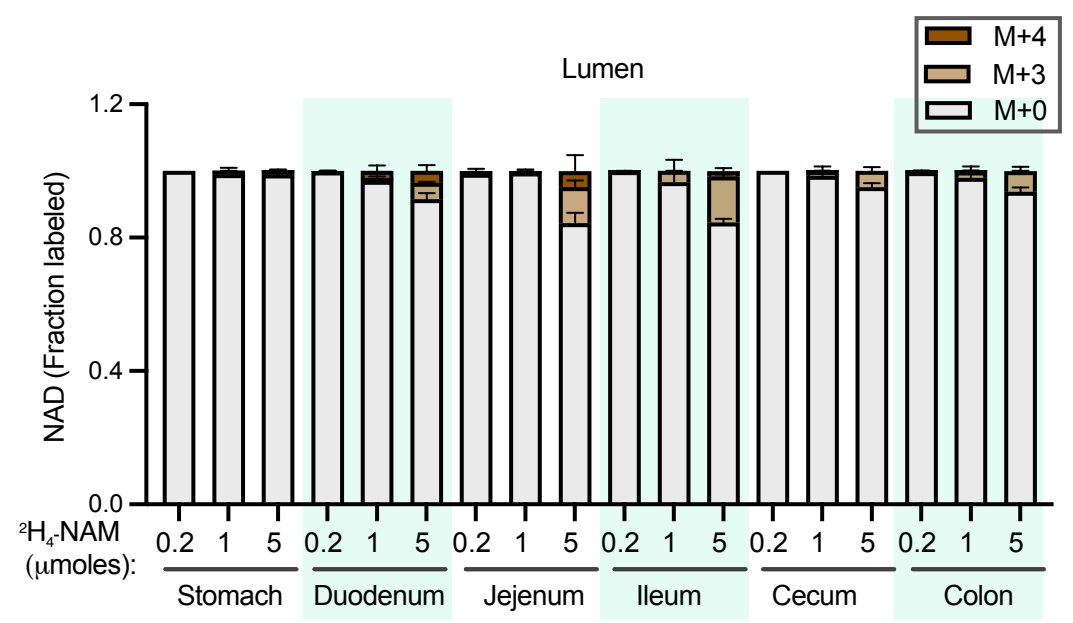

B

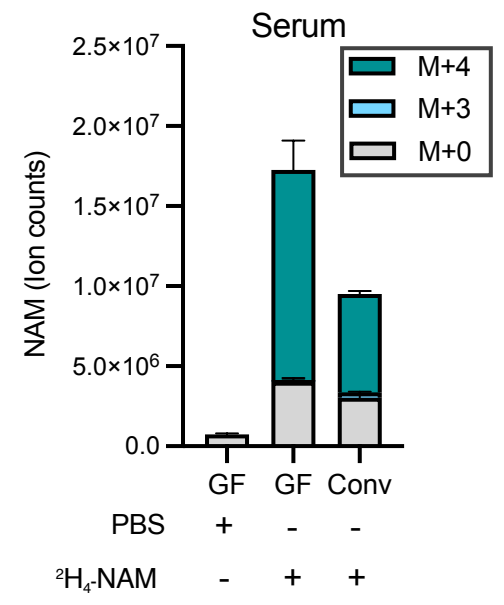

C
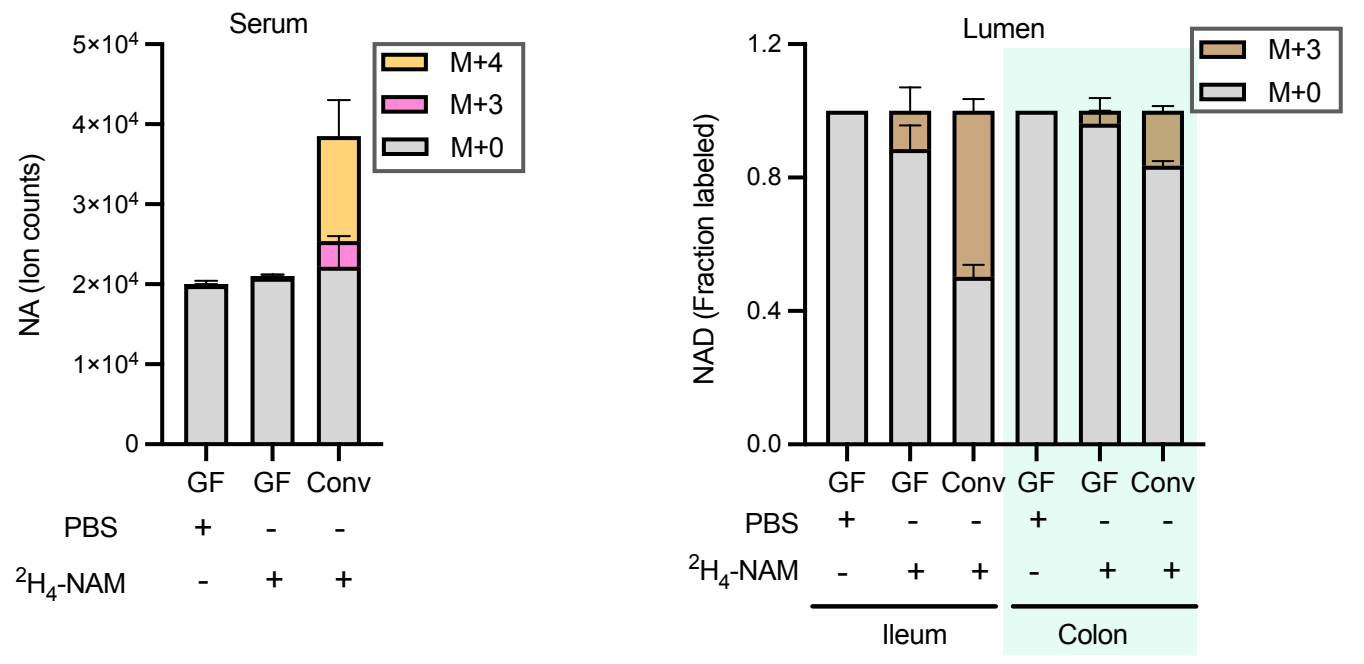
bioRxiv preprint doi: https://doi.org/10.1101/2021.11.15.468729; this version posted November 19, 2021. The copyright holder for this preprint

(which was not certified by peer review) is the author/funder, who has granted bioRxiv a license to display the preprint in perpetuity. It is made available under aCC-BY-ND 4.0 International license.

\section{Supplementary Figure 2. Circulating NAM labels luminal NAD.}

A. Fraction labeled NAD in luminal contents collected from mice retro-orbitally injected with $5 \mu$ moles [2,4,5,6-2H]-NAM and sacrificed after $15 \mathrm{~min} . \mathrm{n}=2-3$ mice per group.

B. NAM levels in the serum samples collected from germ-free (GF) and conventional (Conv) mice $2 \mathrm{~h}$ after retro-orbitally injection of either PBS or $5 \mu$ moles of [2,4,5,6-2 H]-NAM. $n=4$ mice per group.

C. Serum NA labelling in mice treated as in B.

D. Fraction labeled NAD in the luminal samples collected from mice treated as in $B$. 
bioRxiv preprint doi: https://doi.org/10.1101/2021.11.15.468729; this version posted November 19, 2021. The copyright holder for this preprint (which was not certified by peer review) is the author/funder, who has granted bioRxiv a license to display the preprint in perpetuity. It is made available under aCC-BY-ND 4.0 International license.
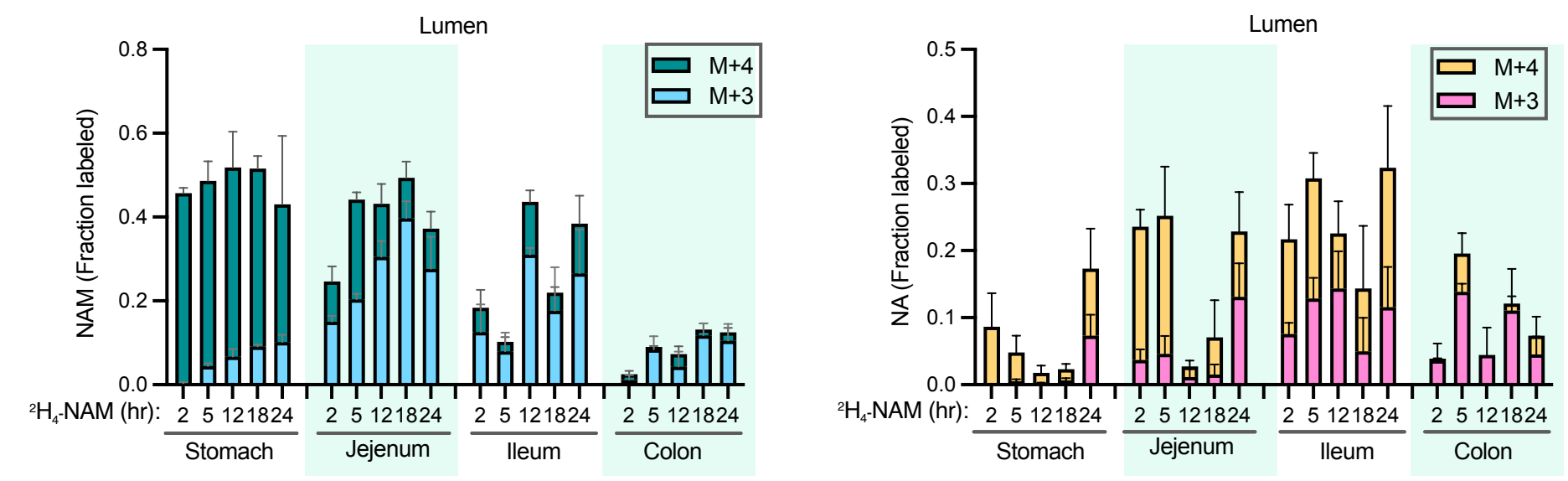

C
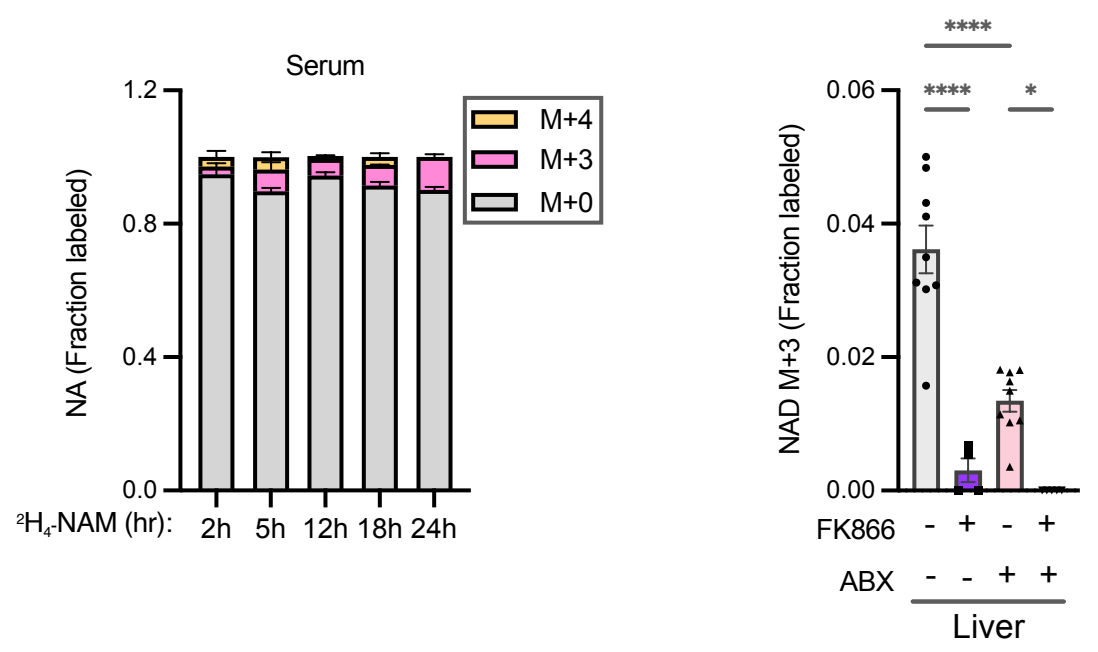


\section{Supplementary Figure 3. The gut microbiome provides metabolic flexibility to bypass salvage synthesis in liver.}

A. Fraction isotope labeling of NAM in the lumen of mice intravenously infused with $4 \mathrm{mM}[2,4,5,6-$ $\left.{ }^{2} \mathrm{H}\right]-\mathrm{NAM} . \mathrm{n}=2-4$ mice per group.

B. Fraction isotope labeling of NA generated by microbial deamidation of $\left[2,4,5,6-{ }^{2} \mathrm{H}\right]-\mathrm{NAM}$ in mice treated as in $\mathrm{A}$.

C. Labeling of serum NA in mice infused as in A.

D. Fraction labeled NAD in the liver from control and antibiotics (ABX) treated mice intraperitoneally injected with vehicle or FK866 and infused with [2,4,5,6-2H]-NAM for 5h. n=3-5 mice per treatment group. 
bioRxiv preprint doi: https://doi.org/10.1101/2021.11.15.468729; this version posted November 19, 2021. The copyright holder for this preprint A (which was not certified by peer review) is the author/funder who has granted bioRxiv a license to display the preprint in perpetuity. It is made available underBCC-BY-ND 4.0 International license.
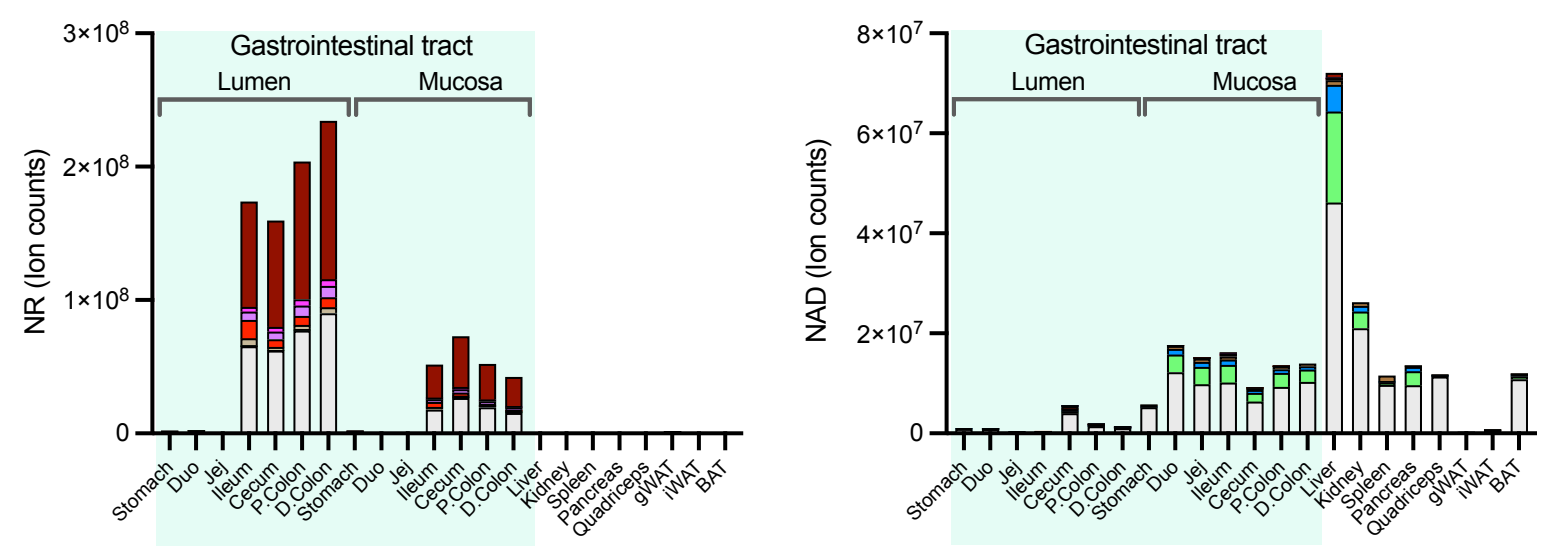

C

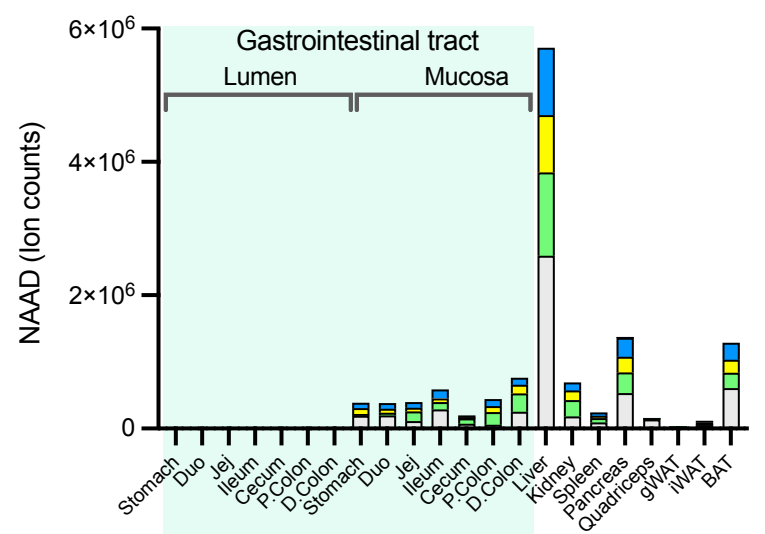

D

E

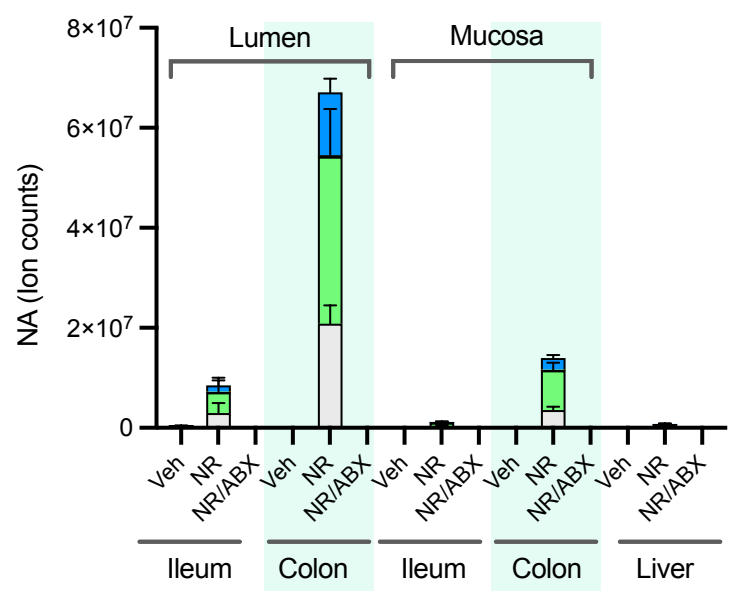

$G$

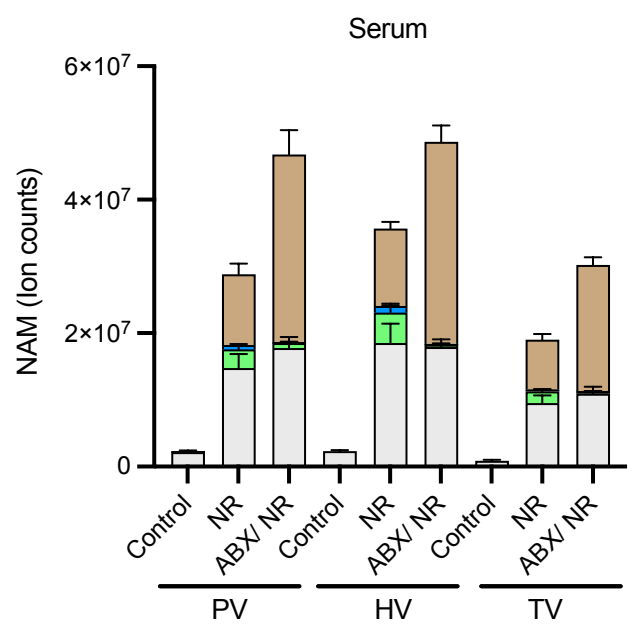

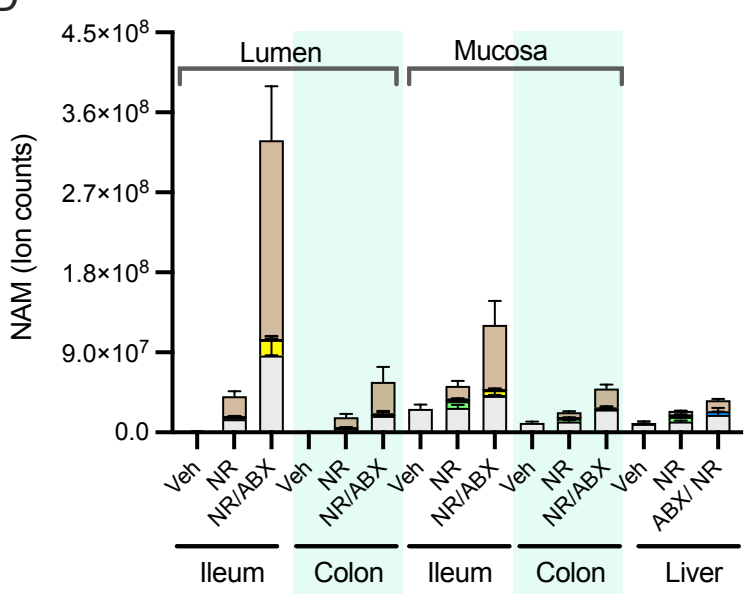

F
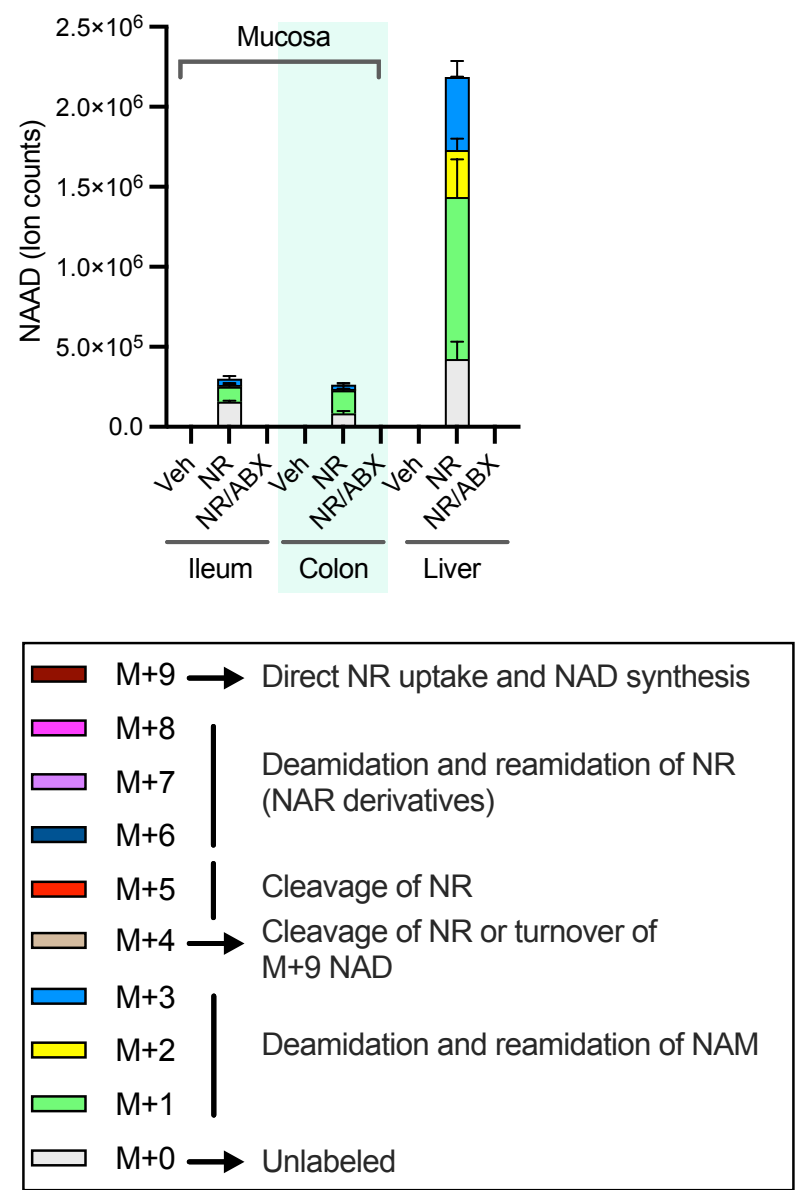
Supplementary Figure 4. The gut microbiome is required to generate deamidated precursors from orally delivered NR.

A-C. NR (A), NAD (B), and NAAD (C) labeling in the lumen and tissues of a mouse orally gavaged with NR at a dose of $600 \mathrm{mg} / \mathrm{kg}$ body weight) for $3 \mathrm{~h}$.

D-F. NAM (D), NA (E), and NAAD (F) labeling in the lumen and tissues of mice orally gavaged with mixture of unlabeled NR at a dose of $600 \mathrm{mg} / \mathrm{kg}$ body weight for $3 \mathrm{~h} . \mathrm{n}=4-5$ mice per treatment group.

G. Serum NAM levels in mice treated as in D. 